\title{
On the universality of ignition delay times of distillate fuels at high temperatures: A statistical approach
}

\author{
Fethi Khaled* and Aamir Farooq* \\ King Abdullah University of Science and Technology (KAUST), Clean Combustion Research \\ Center, Division of Physical Sciences and Engineering, Thuwal 23955-6900, Saudi Arabia \\ *Corresponding authors e-mail: Fathi.khaled@kaust.edu.sa, $\underline{\text { Aamir.Farooq@kaust.edu.sa }}$
}

\begin{abstract}
Ignition delay times (IDTs) of fuels provide very important macro-information about the fuel reactivity and autoignition behavior. IDTs constitute a key metric for fuel/engine co-optimization studies. Chemical kinetic modelling pursuits rely on experimental IDTs as their primary validation target. There have been extensive works in literature on measuring, calculating, modelling and correlating IDTs of a wide range of hydrocarbons, oxygenates, mixtures of pure components and real fuels. Recently, some studies employed a simplified ignition model at high temperatures, comprising of a fast fuel decomposition step and a rate-determining small molecule oxidation step. This description suggests that high-temperature IDT is mainly controlled by the ignition of fuel fragments and is rather weakly dependent on the initial fuel composition. In this work, we study the validity of the hypothesis that IDT of multi-component fuels is weakly dependent on fuel composition under specific thermodynamic conditions. If so, high-temperature IDTs of practical fuels may be described by a universal Arrhenius type correlation. By combining experimental observations and chemical kinetic simulations, we determine the ranges of key parameters (temperature, pressure, equivalence ratio, composition) under which a universal IDT assumption is valid. We conclude that, for fairly random composition and within a $P-T-\phi$ constraint, IDTs of gasolines and jet fuels may be predicted with a high degree of certainty by the following modified Arrhenius expressions $\left(\mathrm{P}=10-80\right.$ bar, $\mathrm{P}_{0}$ $=1$ bar, $\phi=0.5-2$, fuel/air mixtures, units are ms, bar, $\mathrm{K}$, mol, kcal):
\end{abstract}

$$
\begin{aligned}
& \tau_{\text {gasoline }}=6.76 * 10^{-7}\left(\frac{P}{20}\right)^{-1.01} \varphi^{1.13-\frac{1759}{T} \exp \left(\frac{29.39}{R T}\right)}, \\
& \qquad \text { for } T>\frac{1000}{-0.073 . \ln \left(\frac{P}{P_{0}}\right)+\varphi^{-0.0338}+0.0938}
\end{aligned}
$$




$$
\begin{aligned}
\tau_{\text {jet fuel }}=4.46 * 10^{-7}\left(\frac{P}{20}\right)^{-1.21} \varphi^{2.04-\frac{2596}{T}} * \exp \left(\frac{29.33}{R T}\right) \\
\qquad \text { for } T>\frac{1000}{-0.0371 . \ln \left(\frac{P}{P_{0}}\right)+\varphi^{-0.00727}-0.0995}
\end{aligned}
$$




\section{Introduction}

Homogeneous zero-dimensional ignition delay time (IDT) is defined as the time duration that a specific fuel/oxidizer mixture waits, when exposed to specific thermodynamic conditions of temperature and pressure, before exhibiting an ignition process. The ignition may be defined as rapid or exponential heat release as a result of chain branching reactions dominating the reactive system. Homogeneous gas phase IDT is only affected by chemical reactions, and it is different from the ignition phenomenon in practical devices, such as engines, where fuel evaporation, fuel/air mixing, heat transfer, pressure / temperature inhomogeneity and other physical effects can significantly alter the ignition timing or heat release characteristics. Homogeneous IDT is usually measured using shock tubes and/or rapid compression machines. IDT values may vary from few microseconds to few seconds, and it is very dependent on thermodynamic conditions.

Fuel autoignition, described by ignition delay times, is a very important factor in the design and optimization of combustion engines and gas turbines. The combustion phasing in internal combustion engines depends strongly on fuel autoignition behavior and heat release pattern. The octane ratings of fuels are directly linked to their autoignition characteristics. Recent studies have suggested correlations of the octane/cetane ratings (RON, MON, DCN) to homogeneous IDTs [1-4]. Many hydrocarbons, such as n-alkanes larger than C2 (> 2 carbons in their molecular structure), exhibit three distinct regions of reactivity as a function of temperature. At high temperatures, it is well-established that fuel pyrolysis, $\mathrm{H}$-abstraction and $\mathrm{H}+\mathrm{O}_{2}$ chain branching reactions control the ignition process, and IDTs exhibit nearly Arrhenius dependence on temperature $[5,6]$. At low temperatures, ignition of fuels is rather complex where successive $\mathrm{O}_{2}$ additions to the fuel radical (R) and isomerization reactions lead to chain branching pathways [7]. At intermediate temperatures, $\mathrm{O}_{2}$ addition pathways become less dominant and ignition is instead controlled by the formation of $\mathrm{HO}_{2}$ radicals, their conversion to $\mathrm{H}_{2} \mathrm{O}_{2}$ and subsequent decomposition to $\mathrm{OH}$ radicals. The competition between low-temperature chain branching and $\mathrm{HO}_{2}$ formation pathways leads to the negative temperature coefficient (NTC) behavior [8]. The intermediate- and low-temperature pathways are fuel dependent where the chemical structure of $\mathrm{R}$ plays a key role in dictating the fate of the oxidative system [9]. For instance, some molecules, such as n-heptane, show severe NTC feature [10]; some other molecules, such as iso-octane, exhibit shallow NTC feature [11]; while some others, such as toluene [12], ethanol [13] and 
small alkenes [14-16], may not depict any NTC. Such convoluted ignition behavior at low to intermediate temperatures led Khaled et al. [17] to propose relatively complex IDT correlations for fuel blends in the NTC region. However, IDTs in the high-temperature region have been adequately described by modified Arrhenius expressions [5, 6]. These ignition delay time correlations would be valuable in predicting the onset of combustion in complex systems such as IC engines and jet engines by using a time integration as pioneered by Livengood and $\mathrm{Wu}$ [18]. Khaled et al. [17], Yates et al. [19] and Hu et al. [20] successfully used various forms of ignition delay time correlations to predict the onset of ignition in an HCCI engine, a CFR engine and a high-pressure bomb, respectively.

Recently, Wang and co-workers [21-24] have sought to develop a simplistic hybrid chemistry model, termed HyChem, for the high-temperature oxidation of fuels with particular emphasis on jet fuels. The HyChem approach suggests that ignition at high temperature is a two-stage phenomenon, comprising of a fast decomposition step which leads to the formation of smaller intermediates, and an oxidation step where the fuel decomposition products undergo oxidation and lead to ignition. Based on this, Xu et al. [24] observed that IDT of different mixtures of jet fuel components tends to converge to a unique value at high temperatures. This value is independent of fuel composition and only depends on pressure, temperature and equivalence ratio [21] for multicomponent mixtures. Based on wide-ranging experimental IDTs of gasoline and naphtha fuels, AlAbbad et al. [25] and Sarathy et al. [26] recently reported that a number of fuels with different compositions and octane numbers exhibited very similar IDTs at high temperatures. Davidson et al. [27] performed an experimental investigation of the hightemperature ignition delay times of various distillate fuels including gasoline, diesel and jet fuel near stoichiometric conditions, and showed that the IDTs of these distillate fuels are similar within the experimental scatter. They proposed a general correlation for IDTs of distillate fuels over 10 to 60 bar and near stoichiometry [27].

These phenomenological findings, as well as the simplicity of high-temperature ignition process, motivated the current work wherein we propose universal high-temperature IDT correlations for real fuels. The motivation for these universal correlations is to provide standard values of IDTs of real fuels that could be used in application where ignition is an important design factor. We have provided a mathematical reasoning to show that the ignition delay times of real fuels are 
weakly dependent on their exact composition and hence can be used for different streams. We first present a comparison of high-temperature IDTs of pure hydrocarbons, all the way from C4 to $\mathrm{C} 12$, using data from experiments and models. We then introduce the Livengood-Wu ignition delay limit of mixtures of fuels and the theoretical distribution of the IDTs of random mixtures of simple fuels [28]. Finally, we propose modified Arrhenius IDT correlations of two types of real fuels, namely gasoline and jet fuel. We conclude by suggesting how the proposed methodology may be extended to diesels and other fuel streams.

\section{High-temperature ignition delay times (IDTs) of hydrocarbons and oxygenates}

Ignition delay times (IDTs) of pure components are widely studied, experimentally and theoretically, in literature. Detailed chemical kinetic models are readily available for many fuel components. In Fig. 1, we have plotted shock tube IDT measurement of various hydrocarbons and oxygenates, taken from literature [29-33], in stoichiometric air and at a nominal pressure of 13 bar. Small chain and branched hydrocarbons (e.g., n-butane, iso-butane) as well as aromatics (e.g., toluene) have relatively longer IDTs than long chain hydrocarbons (e.g., n-octane, ndecane). At $T \sim 1100 \mathrm{~K}$, the IDTs of these pure components vary by almost one order of magnitude. 


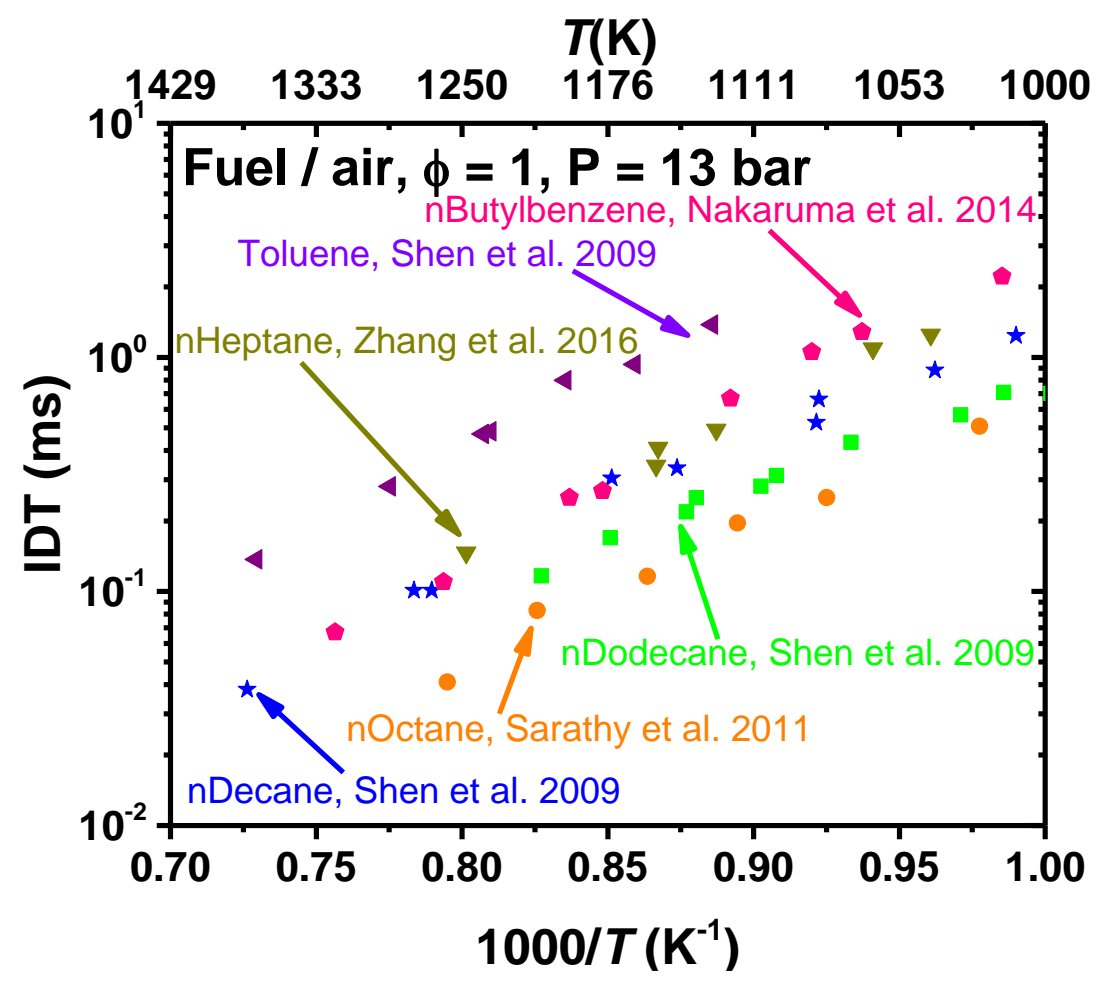

Figure 1: Experimental ignition delay times of various fuels in air at $\phi=1$ and $P \sim 13$ bar. Data taken from references [29-33].

Figure 2 shows calculated homogenous IDTs of 22 gasoline-relevant components (C4 - C8) at $1200 \mathrm{~K}, 20$ bar and $\phi=1$, using the FACE gasoline surrogate model of Sarathy et al. [34]. Calculations were carried out for a homogeneous batch reactor in Chemkin-Pro [35] with constant-UV constraints. The simulated IDTs vary more than an order of magnitude, with benzene exhibiting slowest reactivity and 2-hexene showing highest reactivity within this group of molecules. Based on the experimental and simulated high-temperature IDTs, one may expect that the IDTs of the mixtures of these components would also have a wide distribution. However, as we will discuss in detail later, that is not the case. 


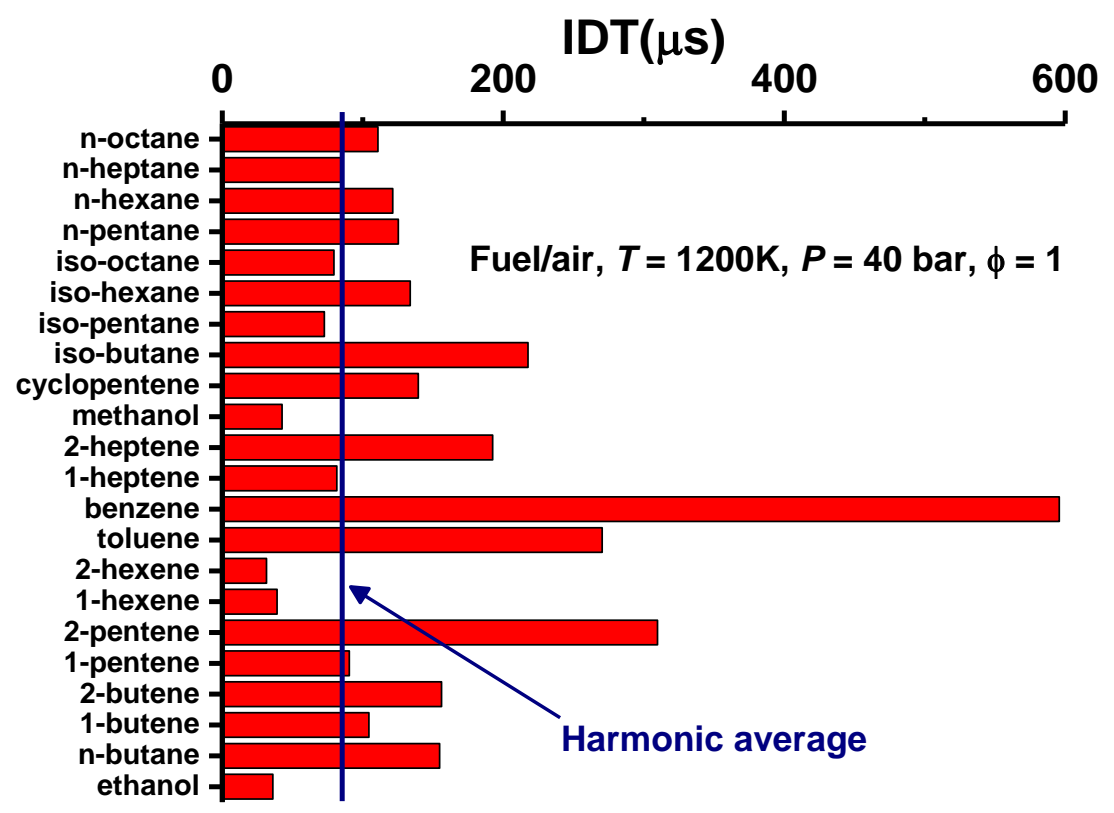

Figure 2: Simulated (Sarathy et al. [34] model) IDTs of various gasoline-relevant components. The harmonic average of IDTs of an equimolar mixture of all these components, as detailed in the next sections, is also shown.

We generated 30 random mixtures, using Dirichlet distribution [36] (mixture composition given in Supplementary Material), comprising of the 22 components (Fig. 2) and calculated IDTs of these mixtures using the FACE gasoline surrogate model [34] in Chemkin-Pro; the distribution of the IDTs of these mixtures is shown in Fig. 3. The distribution is interestingly near-Gaussian shape with relatively low variance and centered on an expected value, denoted as $\tau_{\text {nominal }}$ in Fig. 3. The distribution becomes narrower as temperature is increased from 1000 to $1300 \mathrm{~K}$. Similar findings were recently discussed by Xu et al. [21]. 


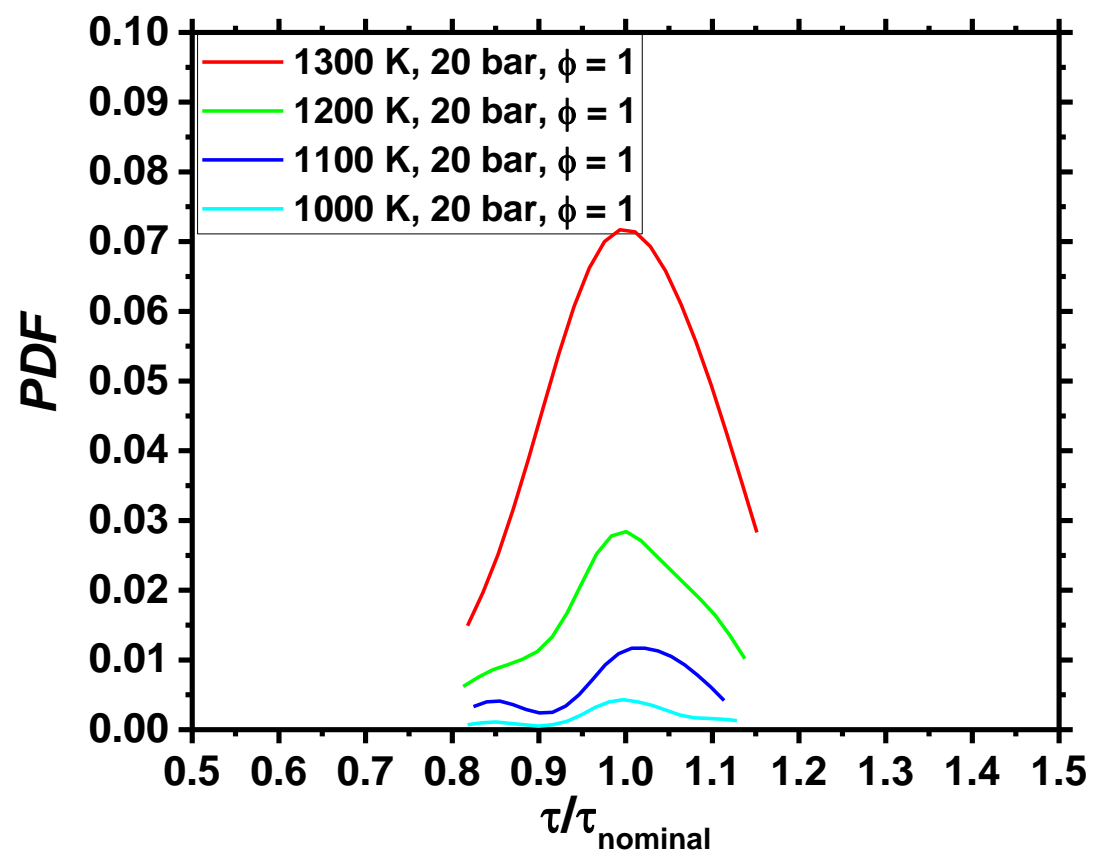

Figure 3: Simulated IDT distribution of a set of 30 randomly generated mixtures (compositions given in Supplementary Material) containing 22 gasoline-relevant components. $\tau_{\text {nominal }}$ is the expected value of the IDTs of all the mixtures.

In the next section, we will show that such a distribution has a mathematical basis. We will then develop a correlation of the IDTs as a function of temperature, pressure and equivalence ratios for gasoline and jet fuel. We will also discuss the temperature, pressure, composition and equivalence ratio boundaries beyond which the universality postulate of IDTs is not valid. 


\section{Mathematical basis of IDTs of random mixtures}

Khaled et al. [17] and Ma et al. [28] have reported that the high-temperature IDT of a fuel mixture or blend, comprising of $n$ components, may be calculated by mole-fraction weighted IDT of each component, $i$ :

$$
\frac{1}{\tau}=\sum_{i=1}^{n} \frac{x_{i}}{\tau_{i}}
$$

The calculated IDT of the fuel blend is labelled here as 'harmonic average'. Equation 1 results directly from the Livengood-Wu description of the ignition phenomenon, as detailed by Khaled et al. [17]. Therefore, at a given thermodynamic condition, the harmonic average IDT $(\tau)$ of a fuel blend may simply be obtained by the calculated or measured IDT $\left(\tau_{\mathrm{i}}\right)$ of each blend component if the mole fraction of each component is known or specified. We calculated the harmonic average IDTs of equimolar mixture of 22 components over a wide range of conditions $(T=900-1300 \mathrm{~K}, P=20-80$ and $\phi=0.5-1.5)$ using the FACE gasoline surrogate model of Sarathy et al. [34], and compared these with the expected IDTs from the distribution of 100 random mixtures (as in Fig. 3); the comparison is shown in Fig. 4. We observe excellent agreement between the high-temperature IDTs obtained by the two methods, which points out that the expected IDT of random mixtures is the harmonic average of the IDT of its components. We will next make use of Eq.1 to show that the observation 'the IDT of random mixtures tends to converge towards a specific value' is mathematically expected. 


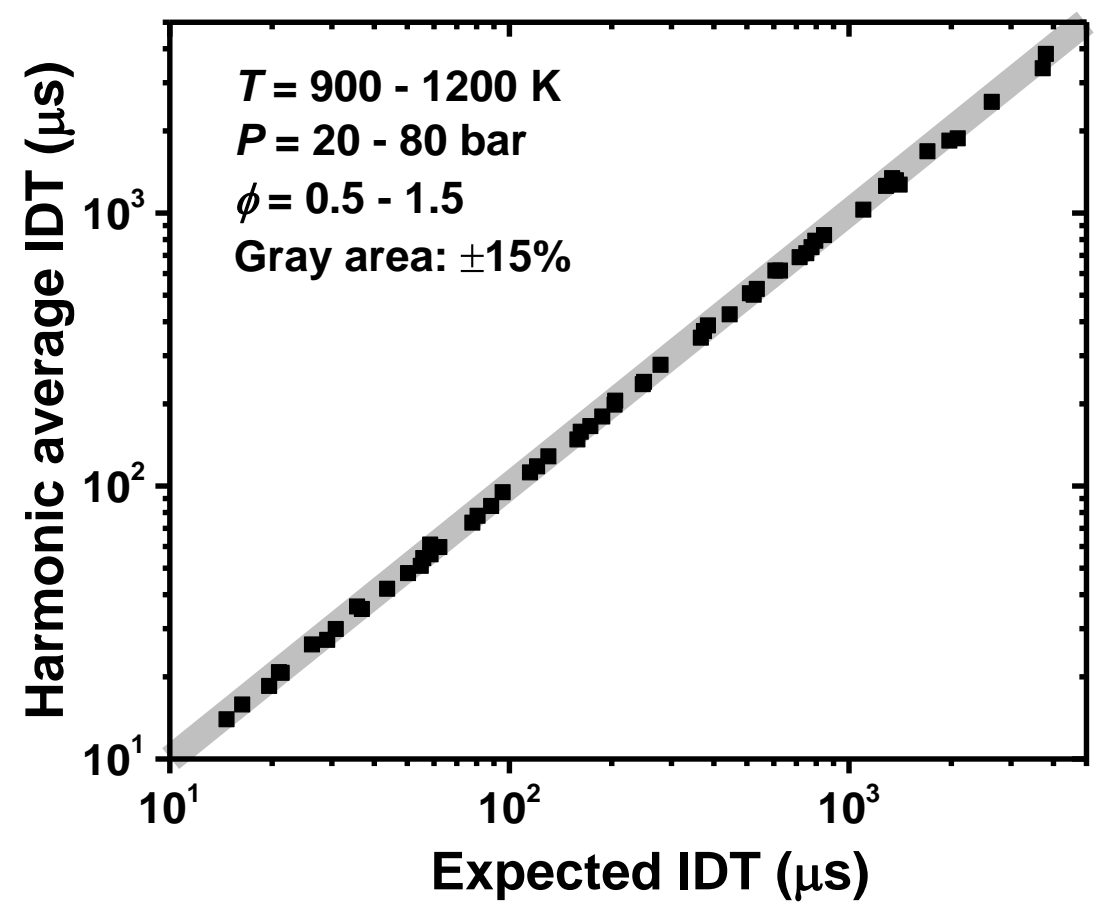

Figure 4: Comparison between the expected IDTs (as in Fig. 3) of random multicomponent mixtures and the harmonic average IDTs of equimolar mixtures.

\subsection{Formulation}

Let $\mathrm{C}_{\mathrm{i}}$ be a set of $n$ components, and let $\mathrm{M}=\left(C_{i}, x_{i}\right)$ be a mixture of these $n$ components with mole fractions $x_{i}$. At any given condition of temperature $T=\mathrm{T}_{0}$, pressure $P=\mathrm{P}_{0}$ and equivalence ratio $\phi=\phi_{0}$, the IDT of each component is given by $\tau_{\mathrm{i}}$, while the IDT $(\tau)$ of M may be obtained using Eq. 1. For a random mixture, each of the composition $x_{\mathrm{i}}$ is a uniform random variable from 0 to 1 , subject to the condition:

$$
\sum_{i=1}^{n} x_{i}=1
$$

The distribution that correctly describes the vector of $x_{i}$ is the well-known Dirichlet distribution [36]. We aim to find the PDF of the IDT of the mixture, based on the relation given by Eq.1. The expected value $(E)$ of the inverse of the IDT may be directly derived since it is a linear property:

$$
E\left(\frac{1}{\tau}\right)=\frac{1}{n} \sum_{i=1}^{n} \frac{1}{\tau_{i}}
$$


We note that, in general, $E\left(\frac{1}{\tau}\right) \neq \frac{1}{E(\tau)}$ which says that the arithmetic average is different from the harmonic average.

Let us define two problems:

$$
\begin{gathered}
P_{1}:\left\{\begin{array}{l}
S_{1}=\sum_{i=1}^{n} \frac{x_{i}}{\tau_{i}} \\
x_{i} \in[0,1] \\
n \\
\sum_{i=1}^{n} x_{i}=1
\end{array}\right. \\
P_{2}:\left\{\begin{array}{l}
S_{2}=\sum_{i=1}^{n} \frac{x_{i}}{\tau_{i}} \\
x_{i} \in[0,1]
\end{array}\right.
\end{gathered}
$$

$P_{1}$ is our problem of interest, whereas $P_{2}$ is a non-constrained problem that seems similar to $\mathrm{P} 1$ but, as we will show, leads to different results.

$P_{2}$ may also be written in this form:

$$
P_{2}:\left\{\begin{array}{l}
S_{2}=\sum_{i=1}^{n} y_{i} \\
y_{i} \in\left[0, \frac{1}{\tau_{i}}\right]
\end{array}\right.
$$

where $y_{i}=\frac{x_{i}}{\tau_{i}}$ is the independent uniformly distributed random variable in $\left[0, \frac{1}{\tau_{i}}\right]$.

The probability density function (PDF) of $S_{2}$ has an analytical expression that can be found in the work of Alvandi et al. [37]. We note here that the expected value of $S_{2}$ is:

$$
\mathrm{E}\left(\mathrm{S}_{2}\right)=\frac{1}{2} \sum_{i=1}^{n} \frac{1}{\tau_{i}}
$$

For the original problem $P_{1}$, the statistics are more complex due to the dependence condition. In the following section, we will give a numerical method to compute the PDF of $P_{1}$. 


\subsection{PDF of the ignition delay time of random mixtures $\left(P_{1}\right)$}

To obtain the PDF of $S_{1}$, we can rely on the Monte-Carlo approach which states that the distribution of enough numbers of random samples converges towards the PDF of the random variable. The mixture mole fractions may be modeled by the Dirichlet distribution [36]. A simple MATLAB code (see Supplementary Material) is written to generate high number of samples $\left(10^{7}\right.$ mixtures), and these are then used to get the PDF of $\mathrm{S}_{1}$.

Using the calculated IDTs of 22 components (see Table 1 ) at a specific condition ( $T=1100 \mathrm{~K}, P$ $=20$ bar, $\phi=1$ ), the PDF generated from the MATLAB code is compared to the normalized PDF obtained for 30 random mixtures from Chemkin simulations (as in Fig. 3). As seen in Fig. 5 , the peak IDT is nearly the same using the two methods, and the variance is less than $20 \%$ with a near-Gaussian distribution. Figure 5 is also a proof that the IDT of mixtures is well represented by Eq. 1 and that the effect of randomness in its composition can be theoretically represented. The fact that the distribution is nearly Gaussian with fairly narrow distribution (and not uniform as one would naïvely expect) points towards the applicability of the postulate that 'the IDT of a blend is weakly dependent on exact composition under some conditions, and is, therefore, somehow universal'. It is important to note here that the universality (independence to the exact mixture composition) of the ignition delay time of fuel mixtures at high temperatures is valid only within certain intervals that will be discussed later.

Table 1: Calculated IDTs at 20 bar, $1100 \mathrm{~K}$ and $\phi=1$. Calculations carried out in Chemkin-Pro using Sarathy et al. model [34].

\begin{tabular}{|ll|}
\hline Component & IDT $(\boldsymbol{\mu s})$ \\
\hline ethanol & 242 \\
n-butane & 909 \\
1-butene & 576 \\
2-butene & 835 \\
1-pentene & 585 \\
2-pentene & 2081 \\
1-hexene & 226 \\
2-hexene & 168 \\
toluene & 2163 \\
benzene & 3904 \\
1-heptene & 505 \\
2-heptene & 1054 \\
methanol & 262 \\
cyclopentene & 743
\end{tabular}




\begin{tabular}{|ll|} 
iso-butene & 1190 \\
iso-pentane & 440 \\
iso-hexane & 683 \\
iso-octane & 544 \\
n-pentane & 724 \\
n-hexane & 738 \\
n-heptane & 524 \\
n-octane & 685 \\
\hline
\end{tabular}

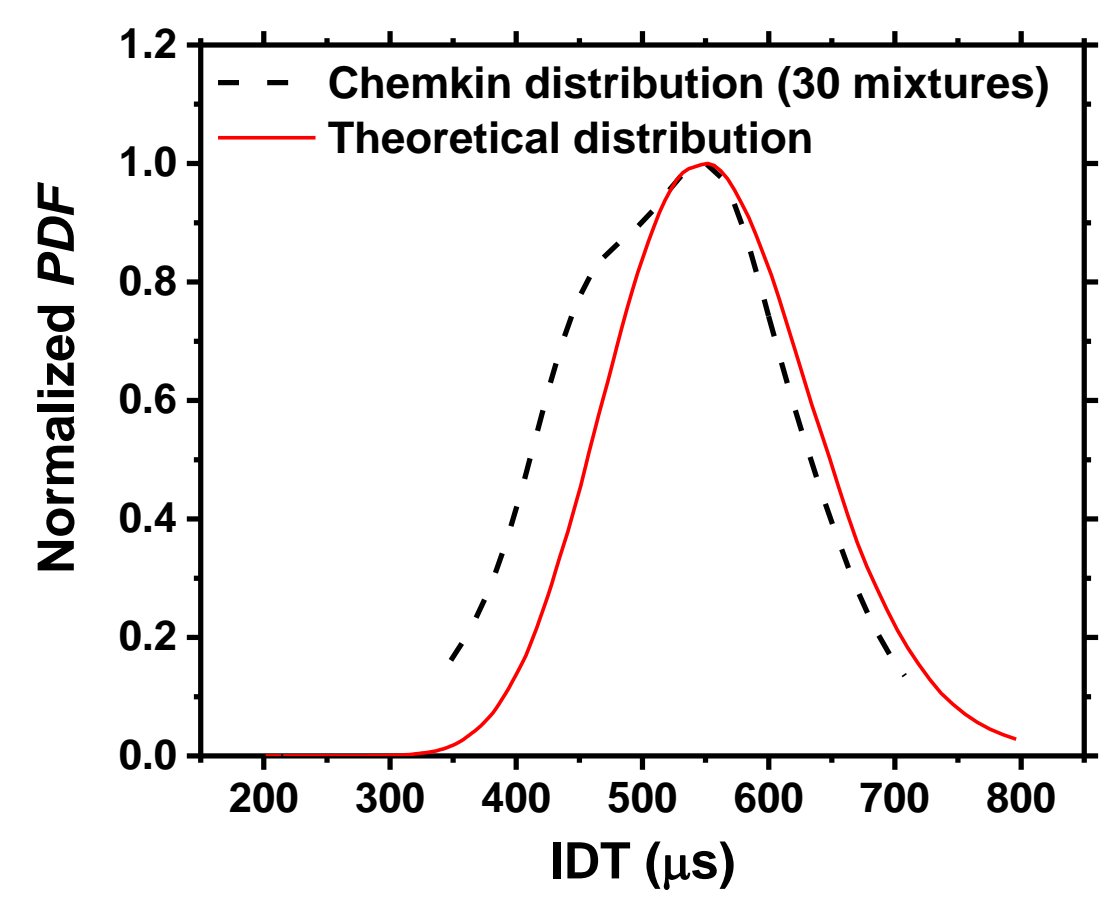

Figure 5: Comparison between theoretical PDF (using MATLAB code) and calculated PDF (using 30 random mixtures in Chemkin-Pro) of mixtures of 22 gasoline-relevant components. $T=1100 \mathrm{~K}, P 20 \mathrm{bar}$, $\phi=1$.

In Fig. 6, we have plotted the theoretical PDF of IDTs, using the Monte-Carlo approach as described earlier, for increasing number of components in the mixture. We can clearly see that, as the mixture comprises of more components, the variance of the PDF of IDT gets narrower around an expected value that is, interestingly, nearly equal to the IDT of an equimolar mixture as given by Eq. 1. We also observe from Fig. 6 that the theoretical PDF for mixtures with 3 components is nearly polynomial per interval. Actually, an analytical formula of the theoretical PDF can be derived for small N (see Appendix). However, the integration exercise becomes very complicated for $\mathrm{N}>3$, and, hence, the Monte-Carlo numerical approach is preferred to obtain the theoretical PDF. 


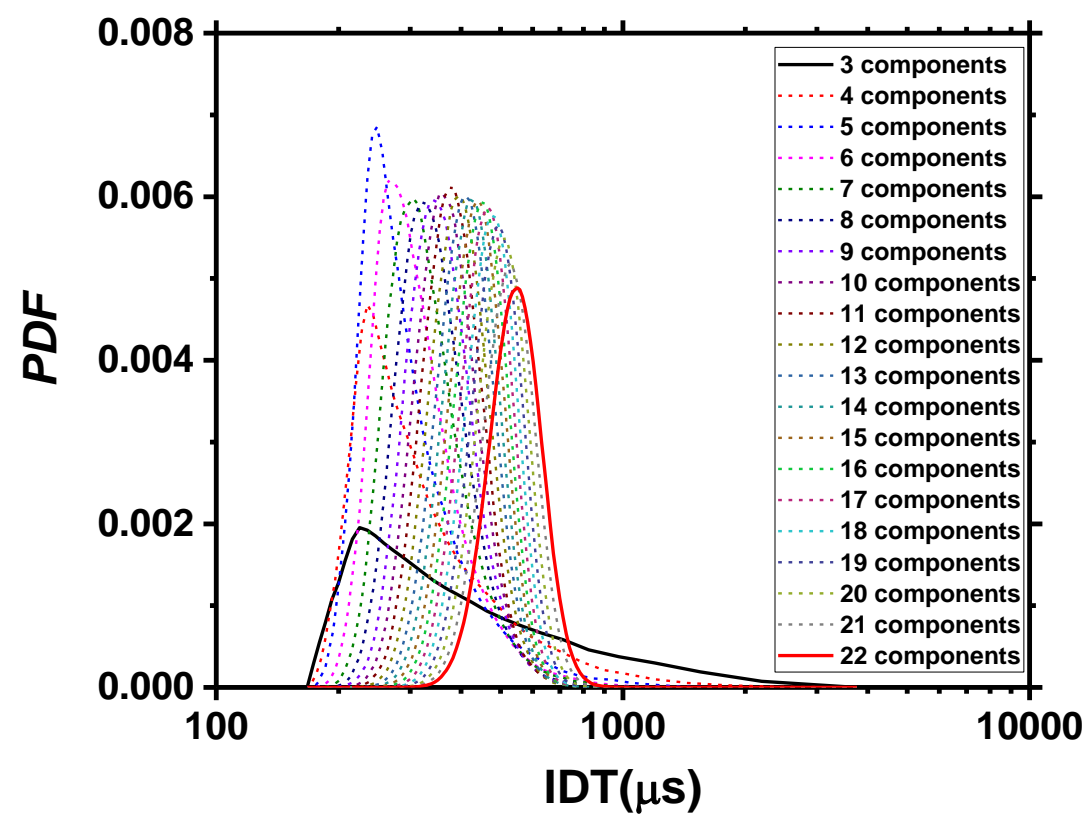

Figure 6: Theoretical PDF of $S_{1}$ for mixtures with varying number of components at 20 bar, $1100 \mathrm{~K}$ and $\phi=1$.

\subsection{Constraints on the mixture composition}

We want to investigate limits of mixture compositions for which one can assume that the IDT of a mixture is universal and is independent of the mixture composition. For our analysis to work correctly, the mixture has to be sufficiently diversified. In other words, if $\sigma$ is a measure of the suitability of the mixture and if the mixture satisfies certain threshold criteria $(\sigma>y)$, then the ignition delay of the mixture will be within $d \%$ of the expected value, where $d$ is the satisfaction level; usually $\pm 15 \%$ is a good satisfaction level for IDTs. Mathematically, we can express this criterion as:

$$
P\left(\frac{\left|\tau-\tau_{\text {nominal }}\right|}{\tau_{\text {nominal }}}<d \mid \sigma>y\right)=1
$$

where, $\tau_{\text {nominal }}$ is the expected value of IDT and $\tau$ is the ignition delay of a specific mixture.

The suitability measure $\sigma$ may be defined in various forms but it has to be maximum for an equimolar mixture for which IDT is equal to the expected value (as in Eq.1). Possible suitability measures are discussed in the Appendix. In here, we follow a phenomenological thinking to 
come up with a convenient suitability measure. Let us have an initial mixture of $n$ - 1 components, then the most probable IDT of that mixture is given by Eq. 1. If we want to add a new component $j$ to the mixture such that the resultant IDT, given by Eq. 1 for $n$, is almost equal to the previous IDT (for $n-1$ ), then we may argue that adding the new component does not appreciably affect the IDT of the mixture. We may write this criterion as:

$$
\frac{\left|\left(\frac{x_{j}}{\tau_{j}}+\frac{1-x_{j}}{n-1} \sum_{i=1^{\prime} i \neq j}^{i=n} \frac{1}{\tau_{i}}\right)-\frac{1}{n-1} \sum_{i=1^{\prime} i \neq j}^{i=n} \frac{1}{\tau_{i}}\right|}{\frac{1}{n-1} \sum_{i=1^{\prime} i \neq j}^{i=n} \frac{1}{\tau_{i}}}<d
$$

Hence:

$$
x_{j}<\frac{d}{\left|\frac{1}{\tau_{j}}-\frac{1}{n-1} \sum_{i=1^{\prime} i \neq j}^{i=n} \frac{1}{\tau_{i}}\right|} \frac{1}{n-1} \sum_{i=1^{\prime} i \neq j}^{i=n} \frac{1}{\tau_{i}}
$$

For the 22 components given in Table 1, this measure gives the following result of the upper bound for the mole fraction of each of the components for $d= \pm 10 \%$ and $d= \pm 15 \%$ :

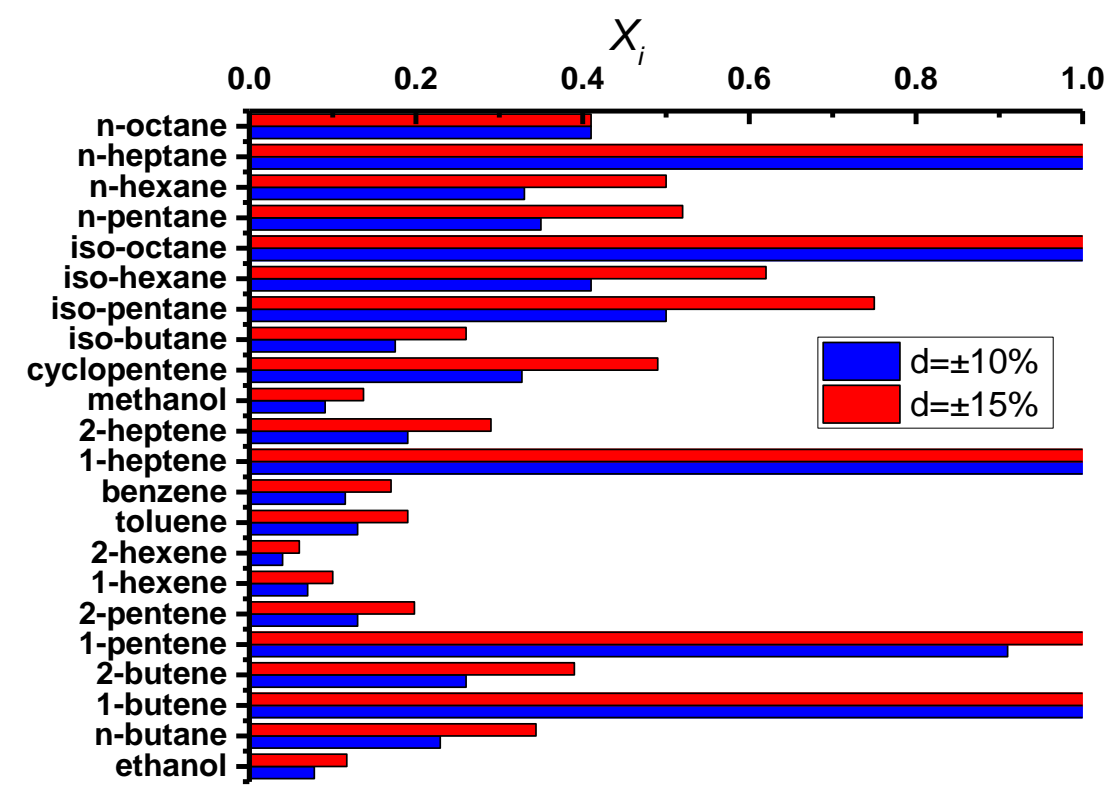

Figure 7: Upper bound of the mole fraction of each component at $\mathrm{d}= \pm 10 \%$ (blue) and $\mathrm{d}= \pm 15 \%$ (red) uncertainties of the IDT from the nominal value obtained at 20 bar, $1100 \mathrm{~K}$ and $\phi=1$.

Figure 7 shows that the constraints on the composition of the mixture are very much dependent on the fuel component, as would be expected from our chemical intuition. Some components, such as 1-hexene, ethanol and toluene, can only be added in small amounts to not perturb the 
mixture behavior. These components have either too high reactivity (e.g., 1-hexene, ethanol) or too low reactivity (e.g., toluene) at high temperatures compared to the gasoline blend. On the other hand, for some components, the upper limit of mole fraction does not actually exist (can go all the way up to 1), such as, n-heptane, iso-octane, 1-heptene, and 1-butene. This is due to the fact that these components have high-temperature reactivity (IDT) similar to that of the blend. This indicates that these specific components can be suitable mono-component surrogates for the high-temperature reactivity of a gasoline fuel. However, a mono-component surrogate may represent the blend reactivity over a narrow range of conditions, as shown in Fig. 8 for n-heptane and iso-octane.

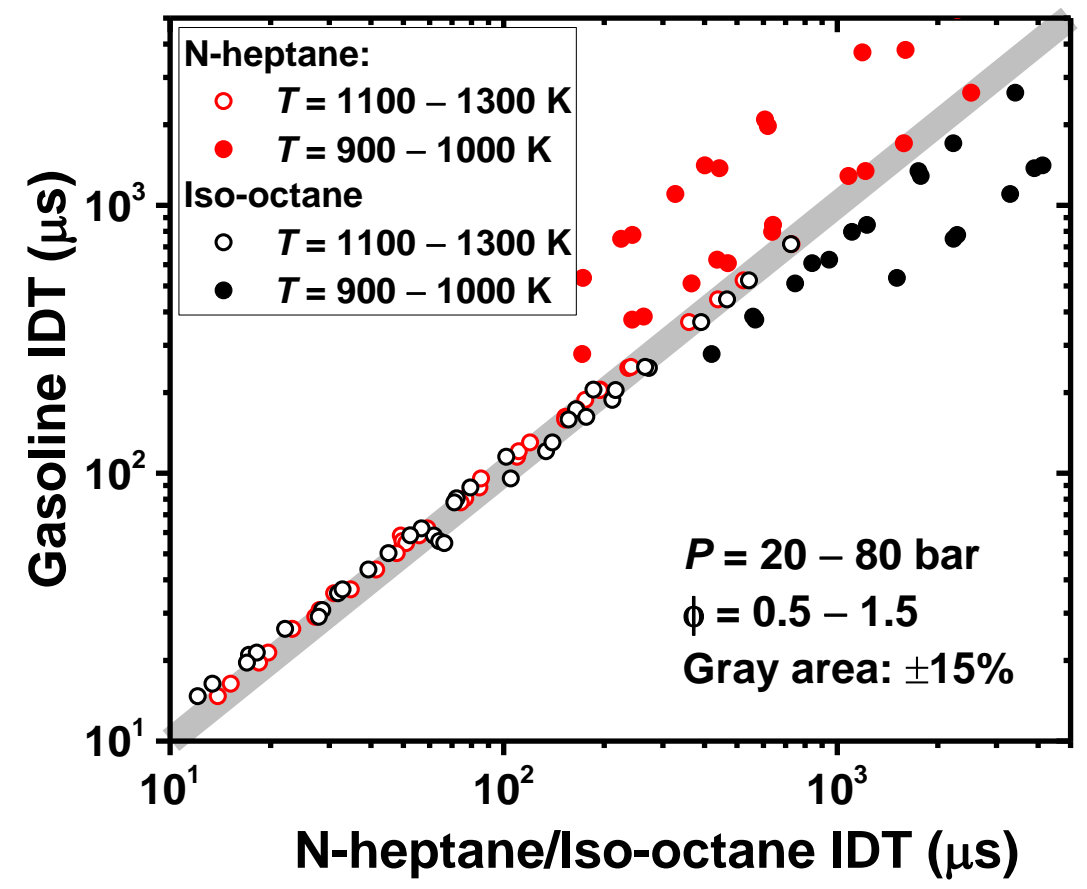

Figure 8: Comparison of gasoline ignition delay times (harmonic average) versus $n$-heptane and isooctane ignition delay times at various conditions of temperature, pressure and equivalence ratio

\subsection{Constraints on thermodynamic conditions}

We would like to stipulate the ranges of temperature and pressure within which the mixture ignitability is not significantly altered by the chemical interactions among fuel components. In other words, as long as Eq. 1 is a good approximation for the IDT of mixtures, the universality of high-temperature IDTs of mixtures, as detailed in the previous section, stands true. However, At low temperatures and high pressures, the Livengood-Wu harmonic average is not valid, as 
explained by Khaled et al. [17], and, consequently, the previous analysis of the theoretical PDF of the IDT of mixtures is not applicable. The criterion for setting the thermodynamic limits within which the IDT of the mixture retains a limiting universal value is the following: temperature, pressure and equivalence ratio should be as such that the PDF of the IDT of random mixtures is fairly narrow; for example, $\pm 15 \%$ variation at the 2 -sigma standard (>95\%, with similarity to the Gaussian distribution). This means that the IDT of the random mixture is within $15 \%$ of the optimal IDT at $95 \%$ confidence. Ji et al. [38] reported the pressure and equivalence ratio of the upper crossover temperature which defines the high-temperature end of the NTC region. Following their work, we may write:

$$
T=\frac{1000}{a_{1} \cdot \ln \left(\frac{P}{P_{0}}\right)+\varphi^{a_{2}}+a_{3}}
$$

where $\mathrm{T}$ defines the lowest temperature above which the IDT of mixtures may be given by the harmonic average IDT of all the components of the mixture, $\mathrm{P}$ is the pressure in bar, $\mathrm{P}_{0}$ is 1 bar, $\phi$ is the equivalence ratio, and $\mathrm{a}_{1}, \mathrm{a}_{2}$ and $\mathrm{a}_{3}$ are fitting coefficients that depend on the palette of components which comprise the mixture.

A T-P- $\phi$ surface, drawn in Fig. 9, of Eq. 8 is obtained using extensive chemical kinetic simulations of 100 randomly generated mixtures and by plotting the PDF of their calculated IDTs at a specific pressure and equivalence ratio, and then decreasing the temperature up to a point where the obtained PDF becomes too wide (>15\% deviation). We note here that these calculations were based on constant-UV homogeneous IDT simulations using the gasoline surrogate mechanism [34] in the pressure range of $10-60$ bar and equivalence ratio range of 0.5 - 1. For the 22 components (Table 1), the coefficients in Eq. 8 are: $\mathrm{a}_{1}=-0.073$, $\mathrm{a}_{2}=-0.0338$ and $\mathrm{a}_{3}=0.0938$. The volume above the surface constraint (see Fig. 9) defines the region where hightemperature universal IDT postulate holds. The trends are in agreement with the general observation that NTC region starts at higher temperature as pressure and / or equivalence ratio increases $[11,30,38]$. As $P$ or $\phi$ decreases, the applicable temperature range increases to lower temperatures. Based on the surface extrapolations in fig.9, We note that even at very high pressures $(\mathrm{P}>80 \mathrm{bar})$ and for fairly rich mixtures $(\phi>2)$, temperatures as low as $1050 \mathrm{~K}$ are in the above the constraint surface which means that the postulate is valid at these conditions, 
thereby allowing the prediction of IDTs for practical conditions in internal combustion engines and gas turbines.

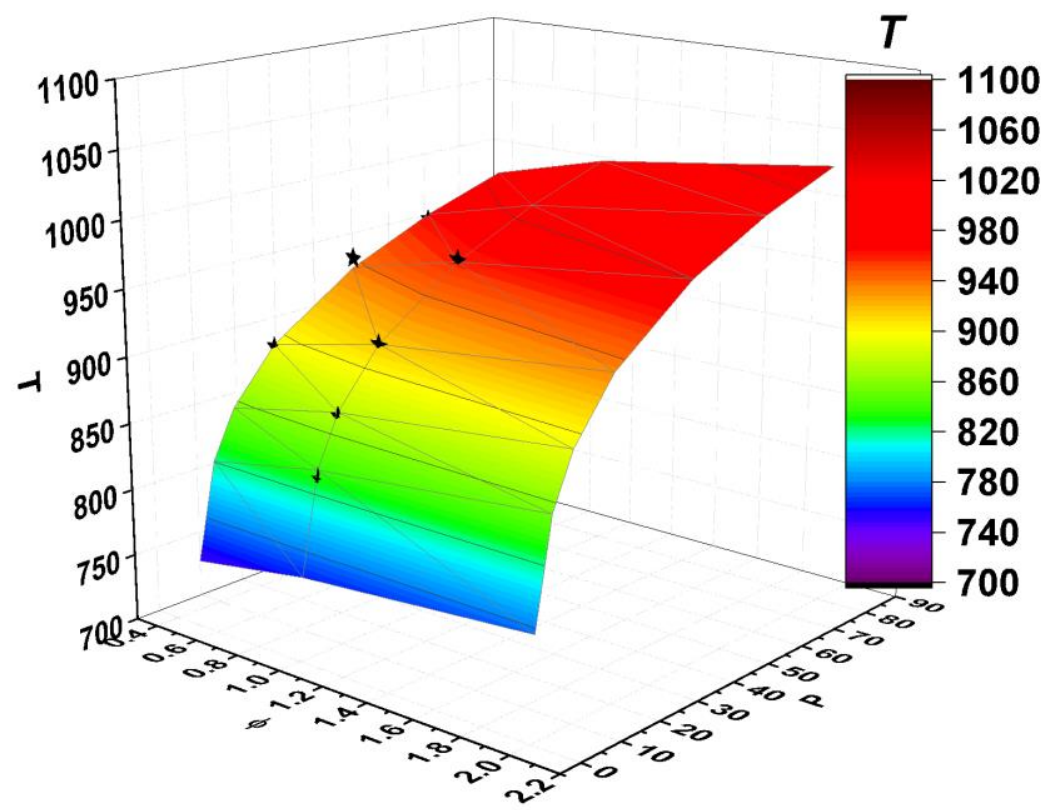

Figure 9: T-P- $\phi$ surface, based on Eq. 8, for mixtures of 22 gasoline components (Table 1). Volume above the surface is the space of thermodynamic conditions where the high-temperature IDT universality is valid. Black stars are the data obtained from Chemkin simulations to fit the surface constraints.

\section{Universal ignition delay correlations}

\subsection{Gasoline}

The illustrative case in the previous section was based on gasoline-relevant components. We extend that discussion here to propose a universal high-temperature ignition delay correlation for gasoline fuels. We carried out IDT simulations using FACE gasoline surrogate model [34] for a gasoline-like mixture (C4-C8), containing the 22 components listed in Table 1, over $T=1000-$ $1500 \mathrm{~K}, P=20-60$ bar and $\phi=0.5-1.5$. The simulated IDTs were then fit to an Arrhenius expression with regression analysis (units are kcal, mol, $\mathrm{K}$, bar and $\mathrm{ms}$ ):

$$
\tau_{\text {gasolines }}=6.76 * 10^{-7}\left(\frac{P}{20}\right)^{-1.01} \varphi^{1.13-\frac{1759}{T}} * \exp \left(\frac{29.39}{R T}\right)
$$

This correlation may be used to predict high-temperature IDTs of any practical multicomponent gasoline fuel as long as composition constraints (Section 4.3) and thermodynamic constraints (Section 4.4) are considered. Although this correlation is developed using simulated data for 
pressures up to 60 bar, we believe that one can use this correlation even at very high pressures (> $100 \mathrm{bar}$ ) and for temperatures as low as $1000 \mathrm{~K}$, thereby allowing the prediction of IDTs for practical conditions in internal combustion engines and gas turbines. For example, based on the surface extrapolation in Fig. 9, we note that even at very high pressures $(\mathrm{P}>80$ bar) and for fairly rich mixtures $(\varphi>2)$, temperatures higher than $\sim 1050 \mathrm{~K}$ are above the constraint surface which means that the postulate is valid at these conditions.

Sarathy et al. [26] reported experimental IDTs of a number of gasoline fuels, with RON ranging from 70 to 100, and showed that at high temperatures (> $900 \mathrm{~K}$ ), IDTs are weakly dependent on RON and fuel composition. These gasolines are all multicomponent mixtures, and should obey the universal rule detailed in the previous section. In Fig. 10, we have plotted Eq. 9 at 20 bar and 40 bar, $\phi=1$ along with the experimental IDT data of gasoline fuels. Literature data for FACE F and FACE G, Coryton and Haltermann, FACE A and FACE C, and FACE I and FACE J are taken from [34, 39-41], respectively. Excellent agreement is observed between the correlation and high-temperature IDT measurements. Figure 10 shows that the distillate fuel correlation of Davidson et al. [27] is in reasonable agreement with our correlation and experimental data. As seen here and discussed later, the Davidson et al. [27] correlation generally predicts faster IDTs for gasoline fuels because it is influenced by the higher reactivity of jet fuels and diesel. Our gasoline IDT correlation is also able to predict the recently reported [42] very high-pressures (up to 250 bar) gasoline IDT data. Since our correlation is based on a wide range of thermodynamic conditions, it is expected to be of wider applicability compared to a correlation developed from limited experimental data. 

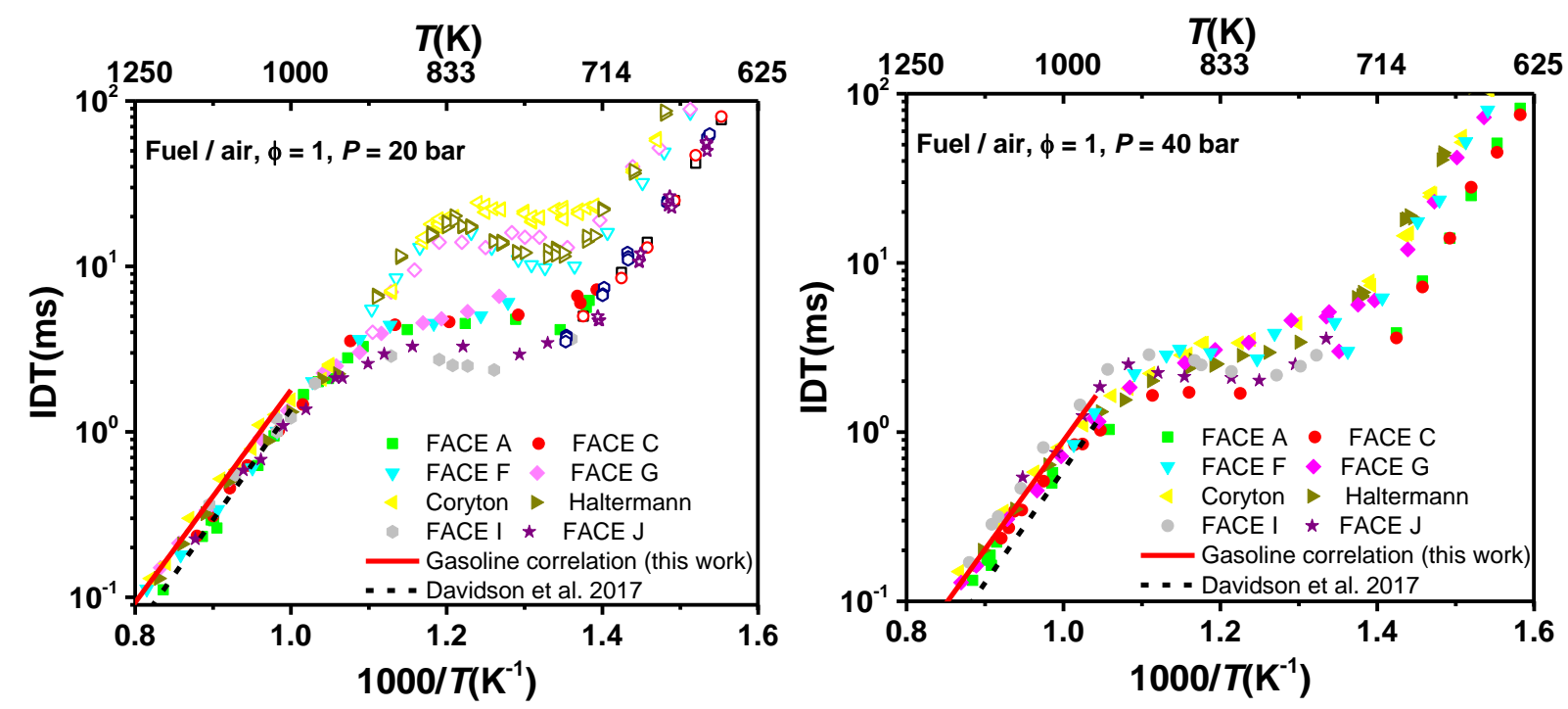

Figure 10: Comparison of high-temperature gasoline IDT correlation (Eq. 9, red line) with experimental IDTs of gasoline fuels (symbols, taken from [26]) and the distillate fuel IDT correlation of Davidson et al.[27] (blue dashed line).

\subsection{Jet fuel}

Composition of jet fuels can vary significantly depending on the refinery source as well as the required usage. Different kind of jet fuels are being used, such as Jet A, S-8, and JP-4. Example of jet fuel composition can be found in Ref. [43]. Jet fuels are mainly composed of paraffins, monocyclo-paraffins, dicycloparaffins, alkylaromatics and naphthalenes. Xu et al. [21] demonstrated the principle of large component for the IDTs of jet fuels at high temperatures. They defined a set of 18 components that represent the hydrocarbons families composing a jet fuel. We note here that their approach to generate the random mixtures was biased towards equimolar mixtures due to randomly assigning a mole fraction and then normalizing these values. This procedure does not quite reach the more robust Dirichlet distribution used in this work. By using the same palette components as Xu et al. [21], we generated a set of 100 random Dirichlet mixtures (Fig. 3S of Supplementary Material) and calculated IDTs of these mixtures using the modified JetSurf [21] for $T=1000-1500 \mathrm{~K}, P=20-60$ bar and $\phi=0.5-1.5$. The simulated IDTs are then fit to a modified Arrhenius expression to obtain universal jet fuel IDT correlation (units are kcal, mol, K, bar and ms):

$$
\tau=9.8 * 10^{-7}\left(\frac{P}{20}\right)^{-0.882} \varphi^{2.039-\frac{2596}{T}} * \exp \left(\frac{29.33}{R T}\right)
$$


Comparison of this correlation with recently published jet fuel ignition data $(\sim 12$ bar $)$ from Davidson et al. [27] and their distillate fuel correlation shows that our correlation (solid line) overpredicts by $\sim 40 \%$ (see Fig. 11).

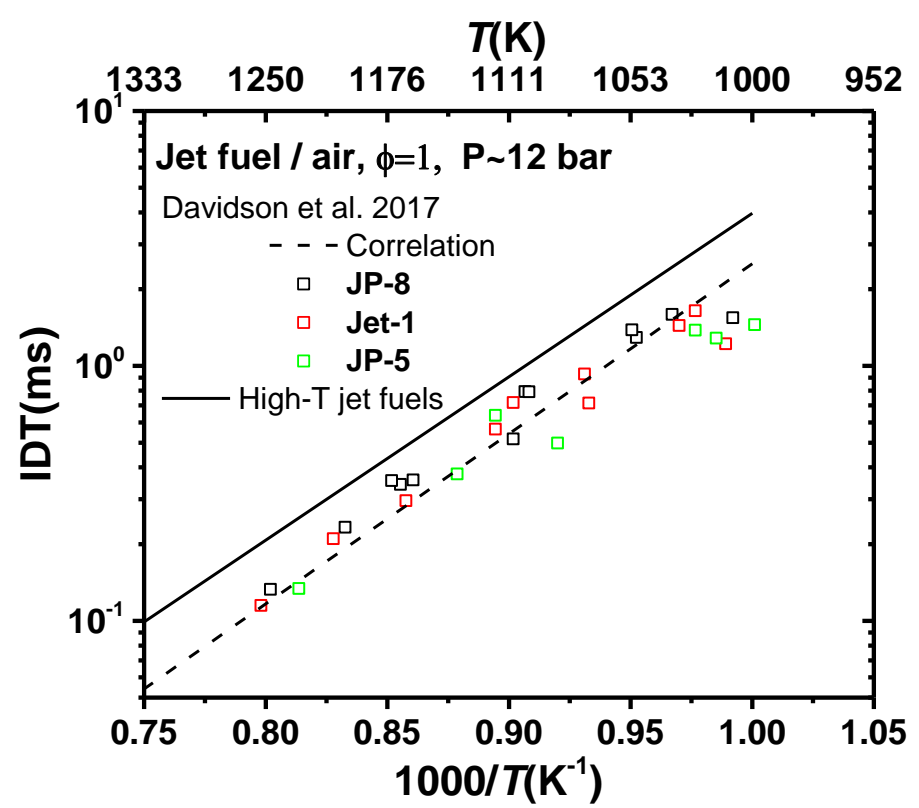

Figure 11: Comparison of jet fuel correlation (Eq. 10) with Davidson et al. [27] jet fuel experimental IDTs and their correlation (dashed line).

The correlation developed with JetSurf model does not accurately predict jet fuel IDTs at other conditions as well, e.g., at higher pressures (see Fig. 14, 20 and 40 bar dashed lines). This discrepancy is either caused by the species palette (18 components) or by the uncertainty in the chemical kinetic models of these species. We varied the palette size and found that the harmonic average IDT does not change significantly when the palette size is larger than 14. This is plotted in Fig. 12 and is in accordance with $\mathrm{Xu}$ et al. [21]. Therefore, it may be argued that the disagreement between our correlation and experimental jet fuel IDTs is caused by the chemistry models of palette components. In Fig. 13(a), we have compared experimental and JetSurf simulated IDTs of methylcyclohexane which shows an overprediction of about a factor of $\sim 2$ by the model over a range of pressures. The effect of the uncertainty of individual IDT prediction on the statistical limit mixture IDT can be assessed by the sensitivity analysis presented in Fig. 13(b). The brute force sensitivity is calculated by inducing a factor of 2 perturbations in the IDT of each component and calculating its effect on the harmonic average IDT. The cumulative effect 
of these uncertainties can result in large deviation between predicted and measured IDTs of jet fuels. This analysis suggests that there is still a need to provide experimental ignition delay data for jet fuel relevant components, particularly branched naphthenes, and to improve the predictive accuracy of corresponding chemistry models.

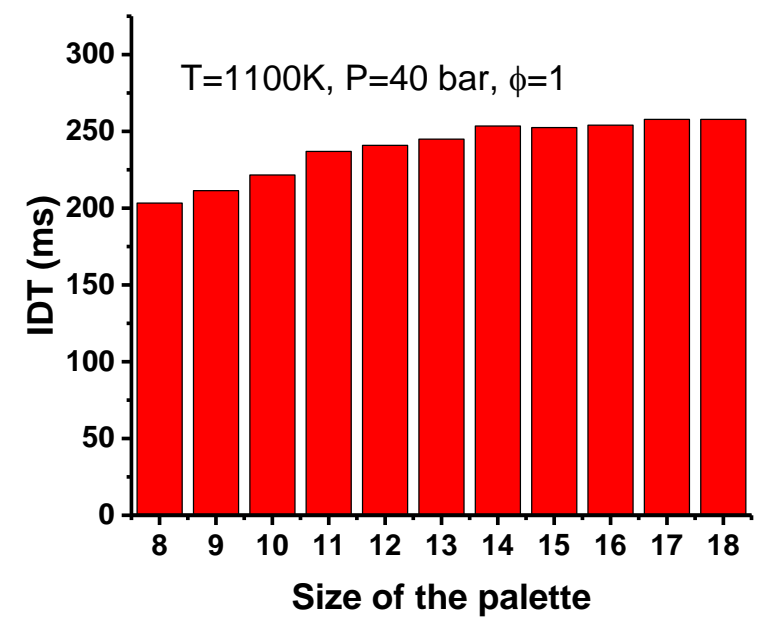

Figure 12: Effect of palette size on the statistical limit IDT of jet fuel/air.
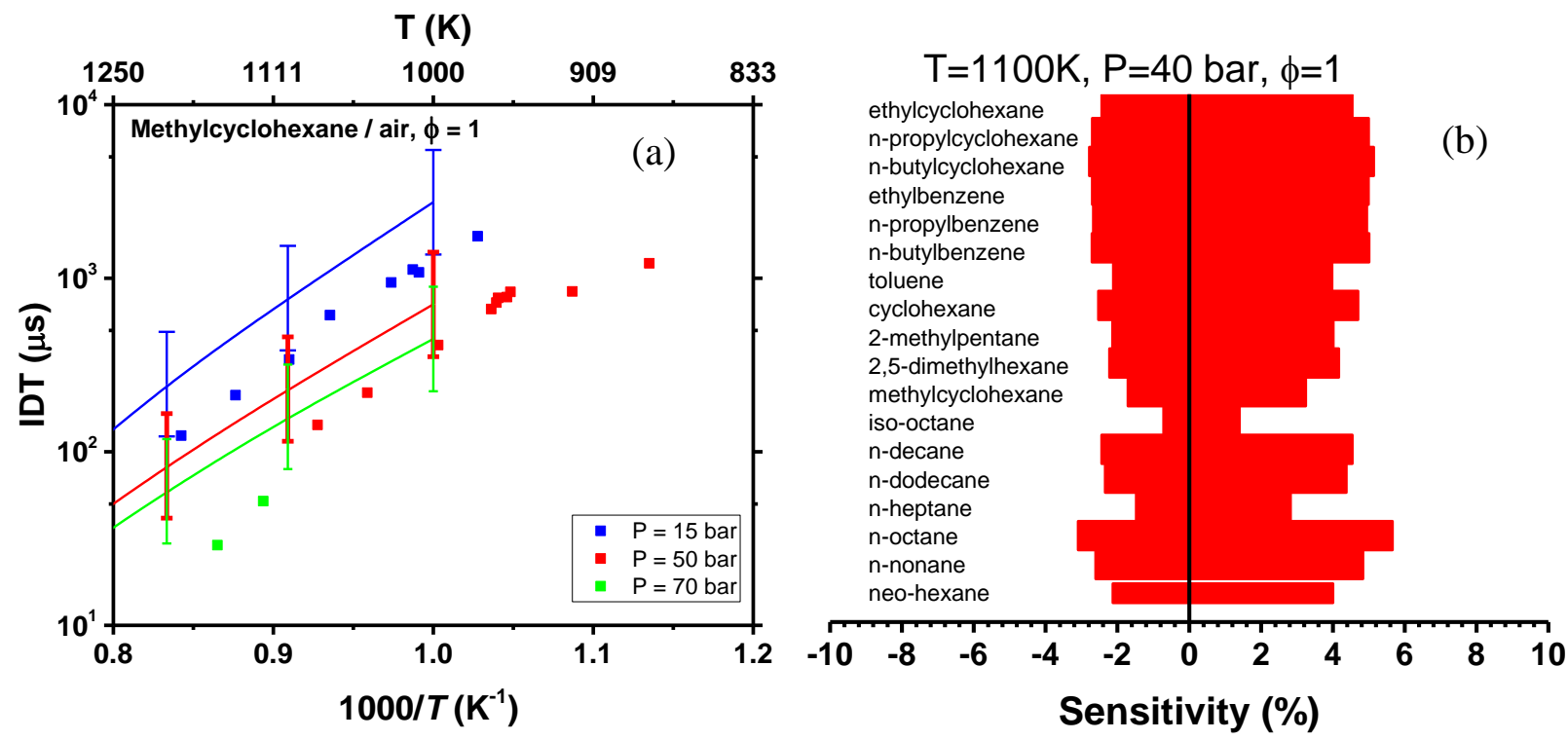

Figure 13: (a) Comparison between experimental (Vanderover et al. [44]) and simulated IDTs with the modified JetSurf model [21]. Representative error bars of a factor of 2 are also shown. (b) Effect of IDT uncertainty on the statistical limit IDT. Each component's IDT is perturbed by a factor of 2 to calculate the change in the harmonic average IDT. 
To overcome the deficiency in the chemical kinetic models of jet fuel components, we modified our correlation with the help of available experimental IDT measurements [44-47] of the 18 pure components comprising the jet fuel palette and/or validated kinetic models [29, 34, 48-50] of these components. The improved and optimized correlation is given as (units are kcal, mol, $\mathrm{K}$, bar and $\mathrm{ms})$ :

$$
\tau_{\text {jet fuel }}=4.46 * 10^{-7}\left(\frac{P}{20}\right)^{-1.21} \varphi^{2.04-\frac{2596}{T}} * \exp \left(\frac{29.33}{R T}\right)
$$

This correlation does a much better job of representing experimental IDTs of jet fuels over a range of pressures, as shown by the solid lines in Fig. 14.

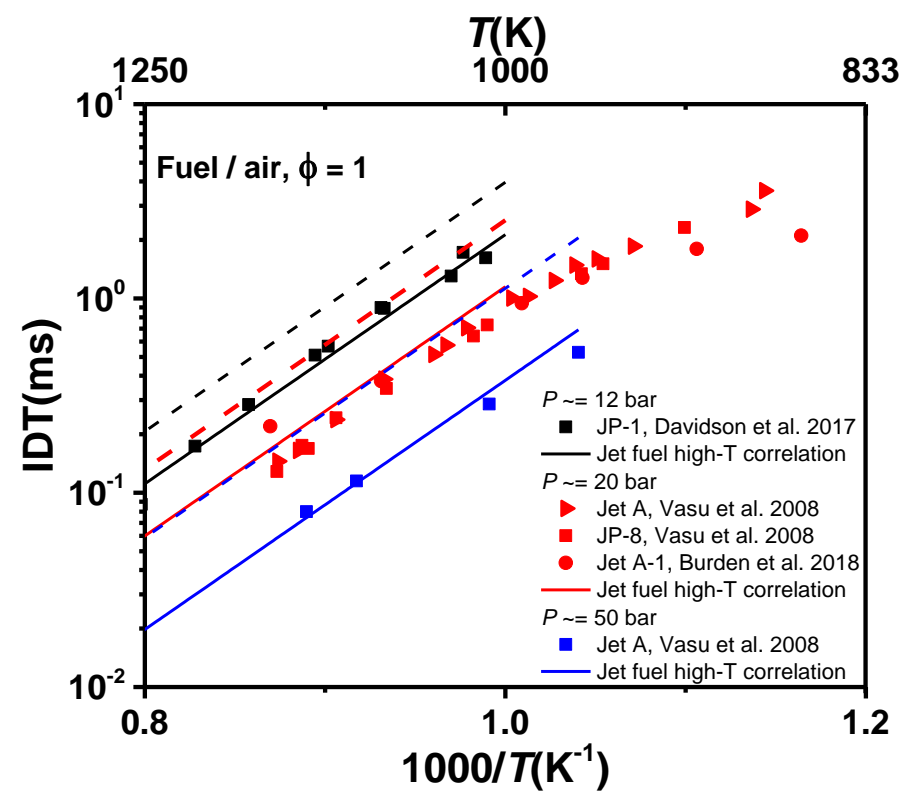

Figure 14: Comparison between our high-T correlation (Eq. 11) of jet fuel IDTs with experimental data from Vasu et al. [51], Davidson et al.[27] and Burden et al. [52]. Dashed lines show the uncorrected jet fuel correlation (Eq. 10).

As discussed for gasoline, Eq. 11 will only be valid within a specific $P$-T- $\phi$ constraint. Extensive chemical kinetic simulations are carried out with the modified JetSurf model [21] to obtain coefficients $\mathrm{a}_{1}=-0.0371, \mathrm{a}_{2}=-0.00727, \mathrm{a}_{3}=-0.0995$ for calculating the $T-p$ - $\phi$ surface with Eq. 8; the surface is plotted in Fig. 15. It is important to note that most of gas turbine relevant thermodynamic conditions are within this $T-p$ - $\phi$ constraint, thus making the universal IDT correlation particularly useful for jet engine studies. 


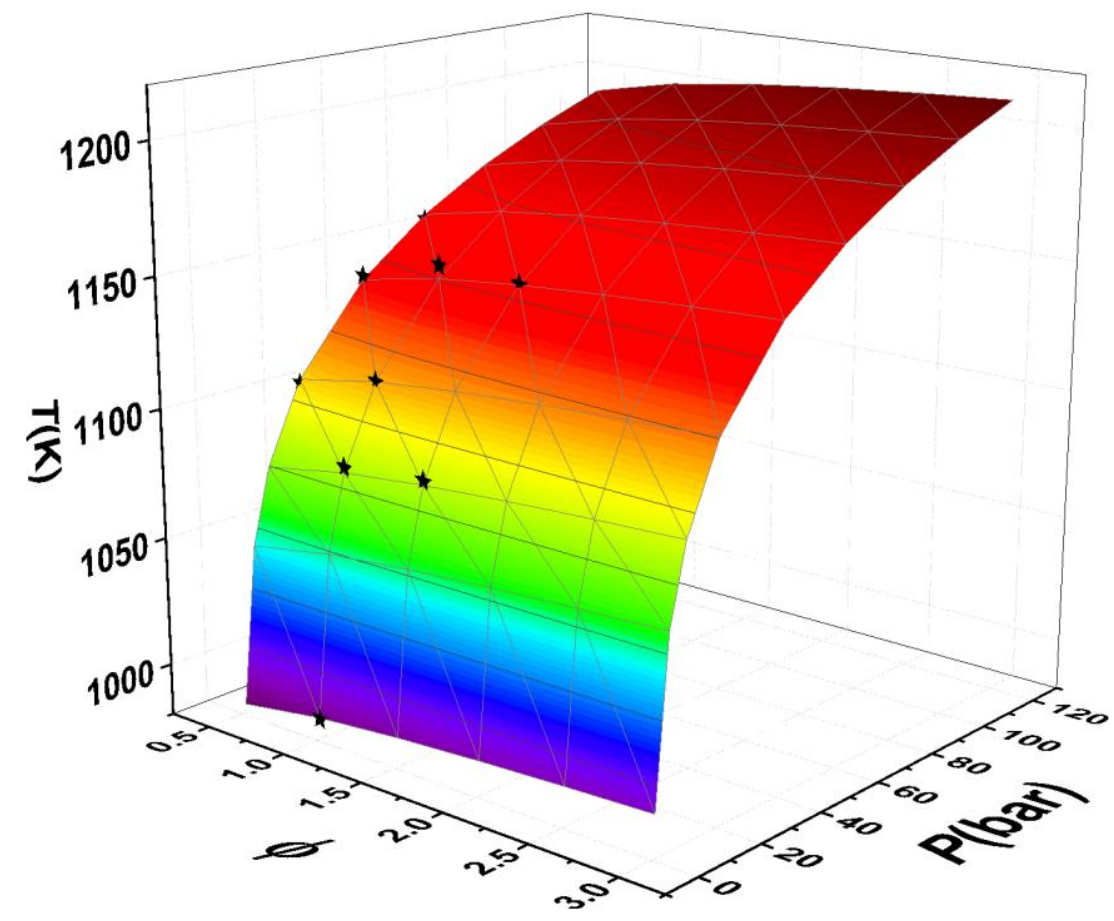

Figure 15: T-p- $\phi$ surface constraint for the applicability of the high-temperature universal IDTs of jet fuels. Black stars are the data obtained from extensive Chemkin simulations used to fit the surface constraints. The IDT correlation is valid in the volume above the surface.

\subsection{Extension to diesel: challenges}

The composition of petroleum-based diesel fuels is highly variable [53-56], with carbon numbers ranging approximately $\mathrm{C} 10$ - C22. Diesels are mainly composed of large n-alkanes, iso-alkanes with one or two side methyl groups, branched cycloalkanes, and alkyl-aromatics [54]. There is very little literature data on the IDTs of diesel components mainly because of their low vapor pressure. Shock tube preheating and the use of aerosol shock tube have been used to generate some data [54, 57-59]. Most of these experiments were performed in diluted argon due to the high boiling points of diesel components. The only experimental ignition delay studies of diesel / air mixtures has been recently reported by Gowdagiri et al. [60] and Davidson et al. [27]. Likewise, very few chemical kinetic models of diesel surrogates are available in literature [61, 62], and the model validation is limited due to the scarcity of available experimental data, particularly at engine-relevant conditions. Table 2 summarizes diesel relevant species for which chemical kinetic models are available in literature. The palette of components in Table 2 is biased towards relatively shorter chain alkanes, shorter branched cycloalkanes and smaller aromatics. The scarcity of chemical kinetic models and experimental data for high carbon 
number diesel components makes it difficult to propose a universal IDT correlation for diesel fuels. Nevertheless, using the components given in Table 2 and extensive chemical kinetic simulations with respective kinetic models, following correlation is obtained for the hightemperature IDTs of diesel fuels (units are kcal, mol, K, bar and ms):

$$
\tau=4.07 * 10^{-7}\left(\frac{P}{20}\right)^{-0.99} \varphi^{1.3-\frac{1927}{T}} * \exp \left(\frac{30.88}{T}\right)
$$

Table 2: Diesel relevant components with available chemical kinetics models

\begin{tabular}{|ll|}
\hline Diesel Components & Chemical Kinetic Model Ref \\
\hline n-octane, n-nonane, n-decane, n-undecane, n-dodecane, & {$[61]$} \\
n-tridecane, n-tetradecane, n-pentadecane, n-hexadecane. & \\
iso-cetane & {$[63,64]$} \\
n-propylcyclohexane, nbutylcyclohexane & {$[65-67]$} \\
decalin & {$[68]$} \\
methylcylcohexane & {$[69,70]$} \\
cyclohexane & {$[71]$} \\
toluene & {$[72]$} \\
n-butylbenzene and n-propylbenzene & {$[33,73]$} \\
methylnaphtalene & {$[74]$} \\
\hline
\end{tabular}

We note here that Sarathy et al. [29] developed a kinetic model for the oxidation of 2methylalkanes up to $\mathrm{C} 20$, and this model also included n-alkanes up to C20 by extending the previously published model of n-alkanes up to C16 by Westbrook et al. [61]. In our work, we did not include n-alkanes larger than C16 since Sarathy et al. [29] did not validate their model for these larger n-alkanes against experimental data.

In Fig. 16, we have plotted simulated IDTs for the various diesel components (Table 2) at 1000 $\mathrm{K}, 20$ bar and $\phi=1 \mathrm{using}$ the respective kinetic models. We have also shown the predicted IDT by Eq. 12 (labelled as 'harmonic average') and the experimental measurement of Gowdagiri et 
al. [60] which is the only work in literature that reported diesel/air IDT measurements at 20 bar. The prediction is higher than the experimental value by a factor of 2 .

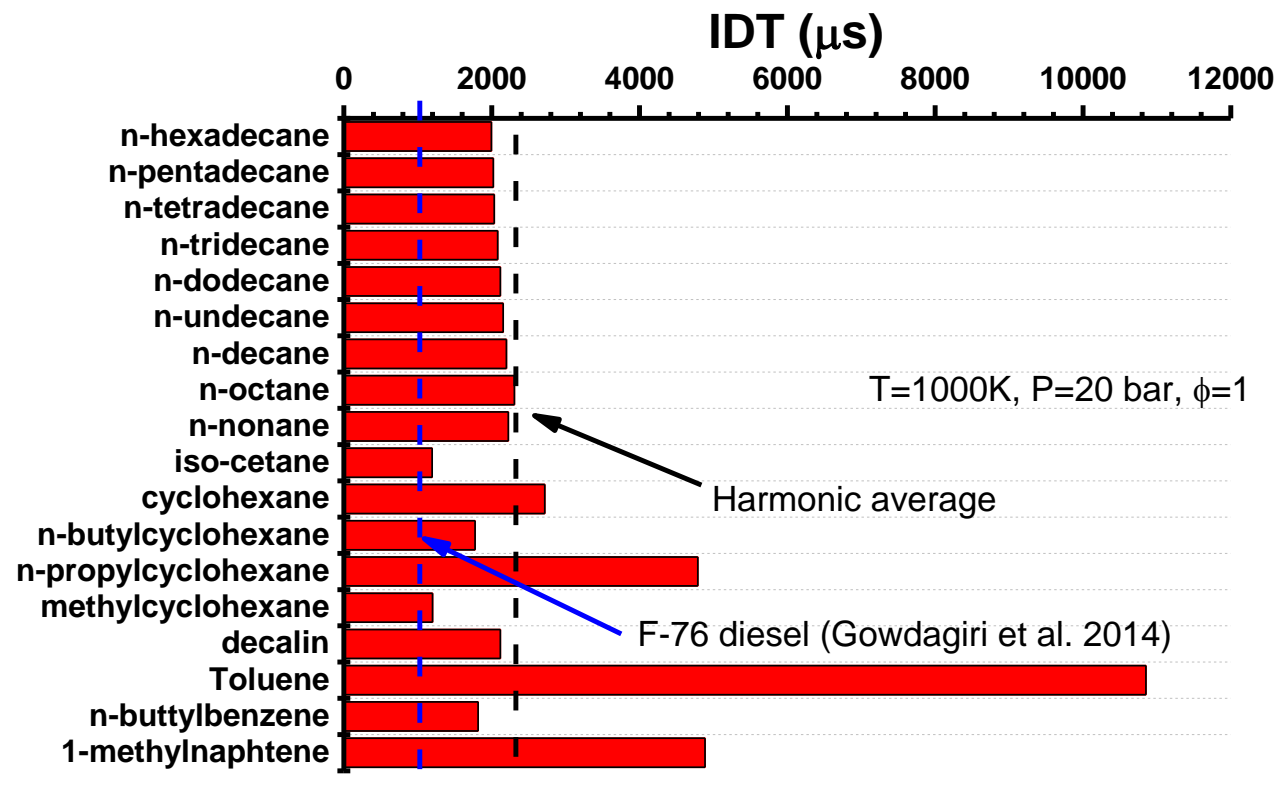

Figure 16: Calculated IDTs of diesel components in air at $1000 \mathrm{~K}, 20 \mathrm{bar}$ and $\phi=1$. Correlated diesel IDT (Eq.12) and experimental measurement of Gowdagiri et al. [60] are also shown.

In Fig. 17, we have further compared diesel IDT correlation (Eq. 12) with stoichiometric ignition delay measurements of F-76 and HDF-76 diesel fuels by Gowdagiri et al. [60] at 20 bar along with data from Davidson et al. [27] at 12 bar and 55 bar (dashed lines). The over-prediction can be explained by the lack of long chain n-alkanes (> C16) and branched cycloalkanes (> C15) in the palette (Table 2) used here. Experimental and modelling studies of such components are needed to further improve our understanding of diesel ignition and to propose an accurate hightemperature IDT correlation. We have attempted to correct the correlation given in Eq. 12 for a better fit with the experimental data in Fig. 17. The new high-T correlation of ignition delay time of diesel, based on calculated values and experimental measurements, is given in Eq. 13 and is plotted in Fig. 17 where good agreement is seen with the experimental data of Gowdagiri et al. [60] and Davidson et al. [27].

$$
\tau_{\text {diesel }}=2.04 * 10^{-7} \cdot\left(\frac{P}{20}\right)^{-1.29} \varphi^{1.3-\frac{1927}{T}} * \exp \left(\frac{30.88}{R T}\right)
$$




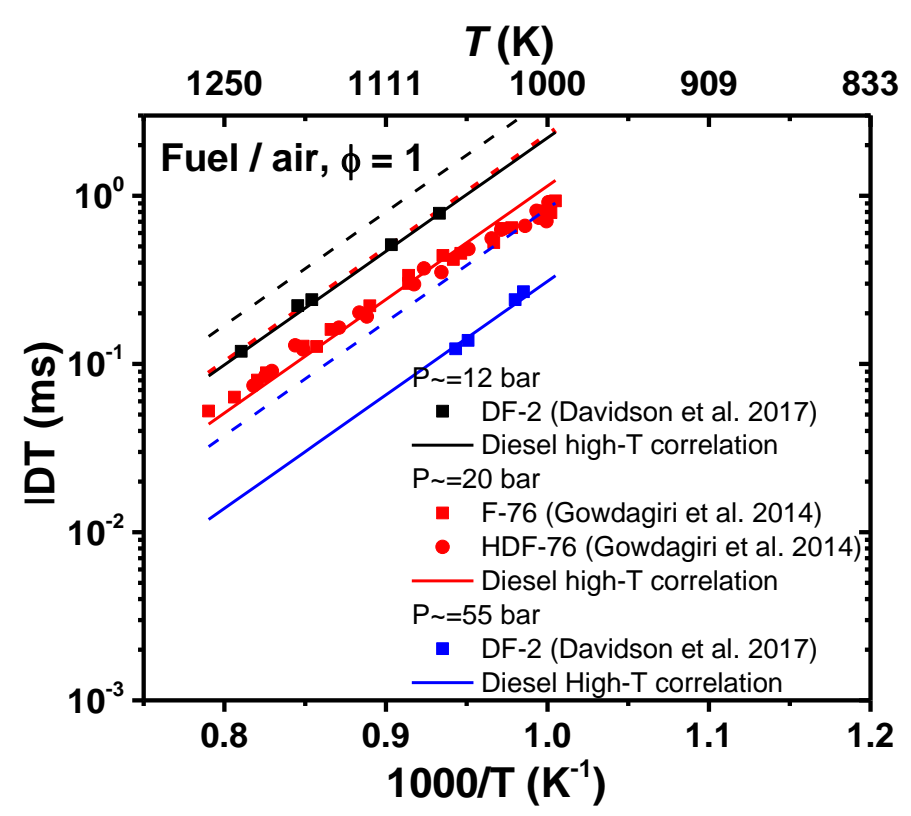

Figure 17: Comparison of experimental IDTs of diesel fuels with diesel IDT correlation (dashed lines, Eq. 12) and corrected correlation (solid lines, Eq. 13).

\subsection{Comparison of high-temperature IDTs of distillate fuels}

Although gasoline, jet fuel and diesel are all multicomponent distillate fuels, their compositions are very different from each other, and, therefore, the composition constraint discussed in Section 4.3 is not valid from one kind of distillate fuel to another. Hence, the differences among IDTs of gasoline, jet fuel and diesel do not contradict the universality of IDTs of multicomponent blends. Davidson et al. [27] provided a unified correlation of the experimental IDTs of gasoline, jet fuel and diesel. Their correlation at stoichiometric conditions showed good agreement with the experimental data. However, the scatter of the data as well as the limited range of thermodynamic conditions of the experiments $(\phi=1$ and $\mathrm{P} \sim 12$ and 55 bar) does not allow one to conclude that high-temperature IDTs of all distillate fuels are same. To illustrate this difference, high-temperature IDT data (taken from [39, 51, 60]) of the three kinds of fuels are compared at 20 bar and $\phi=1$ in Fig. 18. As expected, diesel and jet fuel are more reactive than gasoline; this is typically the case over a broad range of conditions. Therefore, for highaccuracy predictions, it is not reasonable to use a single correlation for IDTs of gasoline and other distillate fuels. On the other hand, high-temperature IDTs of jet fuel and diesel tend to be quite similar except at highly rich conditions. 


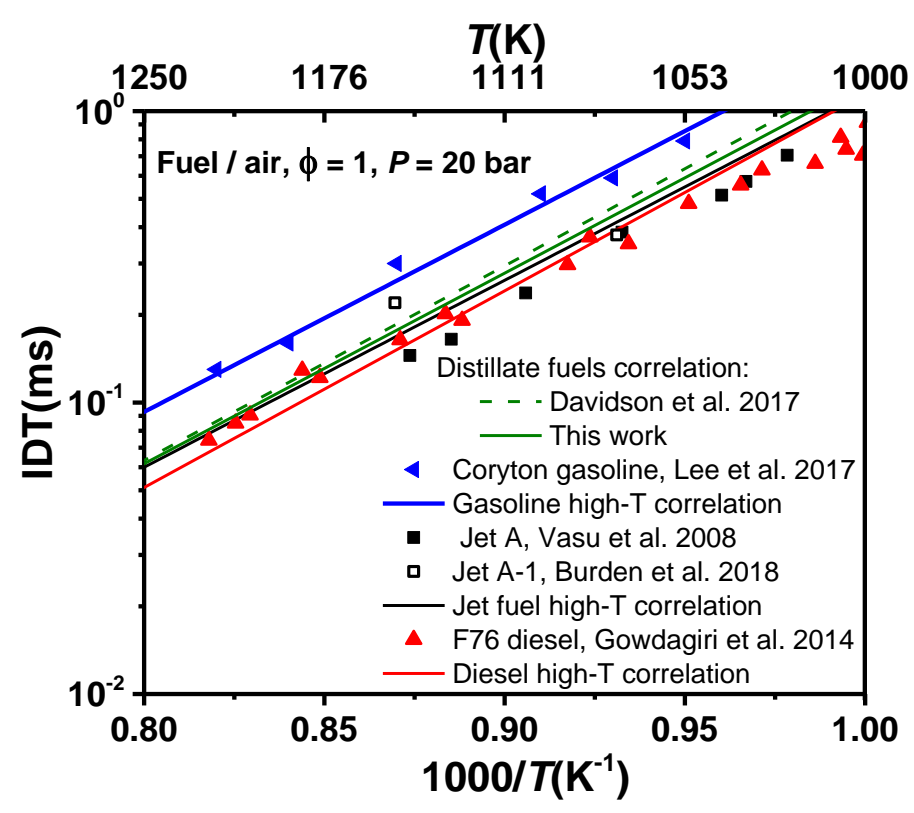

Figure 18: Comparison among high-temperature ignition delay times of gasoline, jet fuel and diesel.

In Fig. 18, we have included the distillate fuel correlation of Davidson et al. [27] which predicts shorter IDTs than the experimental data of Coryton gasoline.

$$
\tau_{\text {distillates }}(\text { Davidson et al. })=2.9 * 10^{-7} \cdot\left(\frac{P}{20}\right)^{-1.194} * \exp \left(\frac{30.54}{R T}\right)(\text { at } \phi=1) \quad \text { Eq. } 14
$$

We have also provided a universal distillate fuel correlation (dashed line in Fig. 18) by taking the harmonic average of our developed correlations for gasoline (Eq. 9), jet fuel (Eq. 11) and diesel (Eq. 13) (units are kcal, mol, K, bar and ms):

$$
\tau_{\text {distillates }}=3.61 * 10^{-7} \cdot\left(\frac{P}{20}\right)^{-1.195} \varphi^{1.76-\frac{2468}{T}} * \exp \left(\frac{29.93}{R T}\right)
$$

It is important to note that the temperature activation energy $(\sim 30 \mathrm{kcal} / \mathrm{mol})$ and the pressure dependence coefficient ( -1.2) are in agreement between our work (Eq. 15) and Davidson et al. [27] (Eq. 14) which further validates the statistical methodology proposed in this work.

The lower reactivity of gasoline, as compared to diesel and jet fuel, may be explained both in terms of the initial composition differences and the different decomposition routes. The key difference between gasoline, jet fuel and diesel is the average molecular size. All of these distillate fuels contain a large fraction of n-alkanes. A gasoline contains mainly n-alkanes from 
$\mathrm{C} 5$ to $\mathrm{C} 8$, a jet fuel contains n-alkanes from $\mathrm{C} 8$ to $\mathrm{C} 12$ and a diesel contains n-alkanes from $\mathrm{C} 10$ all the way to C20 or larger. Simulated IDTs of n-alkanes from C5 to C20 are plotted at $1100 \mathrm{~K}$, 20 bar and $\phi=1$ in Fig. 19(a). We have also plotted 10\% life time (i.e., time of 10\% pyrolysis) of these n-alkanes for $1 \%$ fuel $/ \mathrm{N}_{2}$ at $1100 \mathrm{~K}$ and 20 bar in Fig. 19(b). It is seen that the IDTs of alkanes decrease as the chain length increases and the differences are much smaller for $\mathrm{n}$-alkanes $>$ C9. We also observe that the shorter chain n-alkanes take much longer to undergo pyrolysis due to the relatively higher ratio of primary/secondary C-H bonds. Figure 19(c) plots the ratio of the maximum concentration of propene (relatively low reactivity) to that of ethylene (relatively high reactivity) during the ignition process of n-alkanes from C5 to C20. These two small hydrocarbons are the two main intermediates formed from the decomposition of n-alkanes. It is clear that n-alkanes up to $\mathrm{C} 8$ form higher amount of propene which would explain their low reactivity compared to n-alkanes > C9. In line with the HyChem description, the hightemperature ignition of $n$-alkanes is directly correlated to their pyrolysis rate and pyrolysis products, which seems to converge as the chain length increases. The effect of chain length on reactivity tends to be less prominent as the chain length increases for $\mathrm{n}$-alkanes. This simple analysis illustrates the similarity between IDTs of diesel and jet fuel as compared to gasoline. 


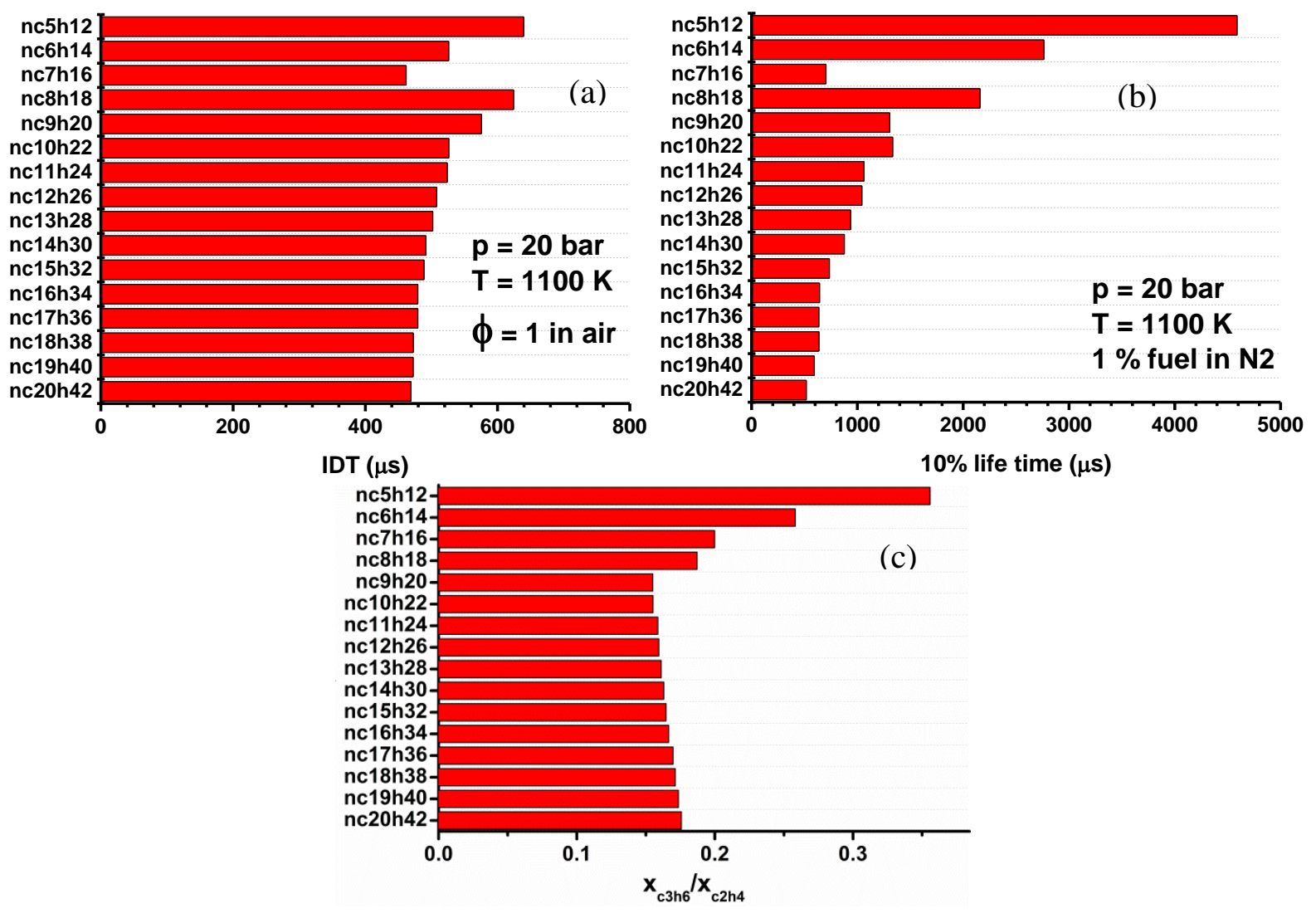

Figure 19: Effect of chain length of n-alkanes on their reactivity: (a) ignition delay times at 20 bar, 1100 $K, \phi=1$ in air (b) time for the pyrolysis of $10 \%$ of the initial fuel at $1100 \mathrm{~K}, 20$ bar for $1 \%$ n-alkane in $\mathrm{N}_{2}$. (c) Ratio of the maximum mole fraction of propene to that of ethylene formed at the conditions of (a). Simulations are performed using the kinetic model of Sarathy et al. [29].

\section{Conclusions}

We have presented detailed mathematical and modelling proof of the universality of IDTs of real fuels at high temperatures due to the presence of large number of components and the simplicity of high-temperature ignition phenomenon. We based our analysis on the Livengood-Wu description of the ignition process, which predicts that the high-temperature IDT of a mixture is the harmonic mean of the components' individual IDTs. This procedure enabled us to suggest constraints on temperature, pressure and compositions over which the universality of IDTs holds. We applied our methodology to three types of real fuels, namely gasoline, jet fuel and diesel. We have provided modified Arrhenius expressions which can be used to predict their IDTs at high temperatures as a function of pressure, temperature and equivalence ratio. The proposed correlations for jet fuel and diesel needed some correction due to the lack of validated chemical 
kinetic models and experimental data of their representative blend components. We observed very good agreement of our correlations with available experimental IDT data of gasoline, jet fuel and diesel. We believe that these simple correlations can be highly useful in engine design and optimization studies where fuel autoignition is an important factor.

\section{Acknowledgement:}

Research reported in this work was funded by King Abdullah University of Science and Technology (KAUST). We are thankful to Prof. Omar Knio (CEMSE Division, KAUST) for helpful discussion on random numbers. 


\section{Appendix}

\section{Appendix A: Analytical PDF of the IDT of random mixtures}

The problem $\mathrm{P}_{1}$ is multidimensional and finding the exact analytical solution for its PDF is a hard exercise. In the following, we report the PDF (probability density function) and CDF (cumulative density function) for relatively simple cases (up to $\mathrm{N}=3$ ).

i. $\quad \mathrm{N}=1$

$$
\begin{gathered}
S_{1}^{1}=\frac{X_{1}}{\tau_{1}} \\
f_{S_{1}^{1}}(t)=\left\{\begin{array}{cc}
0 & ; t<0 \\
\tau_{1} ; & 0 t \leq \frac{1}{\tau_{1}} \\
0 & ; t>\tau_{1}
\end{array}\right. \\
F_{S_{1}^{1}}(t)=\left\{\begin{array}{cc}
0 & ; t<0 \\
\tau_{1} . t & ; 0 \leq t \leq \frac{1}{\tau_{1}} \\
1 & ; t>\frac{1}{\tau_{1}}
\end{array}\right.
\end{gathered}
$$

ii. $\quad \mathrm{N}=2$

$$
\begin{gathered}
S_{1}^{2}=\frac{X_{1}}{\tau_{1}}+\frac{X_{2}}{\tau_{2}} \\
F_{S_{1}^{2}}(t)=P\left(\frac{X_{1}}{\tau_{1}}+\frac{X_{2}}{\tau_{2}}<t\right)=\int_{-\infty}^{+\infty} P\left(\frac{X_{1}}{\tau_{1}}+\frac{X_{2}}{\tau_{2}}<t \mid X_{2}=x_{2}\right) \cdot f_{X_{2}}\left(x_{2}\right) d x_{2} \\
=\int_{0}^{1} P\left(\frac{1-x_{2}}{\tau_{1}}+\frac{x_{2}}{\tau_{2}}<t\right) \cdot f_{X_{2}}\left(x_{2}\right) d x_{2} \\
=\int_{0}^{1} P\left(x_{2}<\frac{t-\frac{1}{\tau_{1}}}{\frac{1}{\tau_{2}}-\frac{1}{\tau_{1}}}\right) d x_{2}
\end{gathered}
$$




$$
\begin{gathered}
F_{S_{2}}(t)=\left\{\begin{array}{c}
0 \quad ; t<\frac{1}{\tau_{1}} \\
\frac{t-\frac{1}{\tau_{1}}}{\frac{1}{\tau_{2}}-\frac{1}{\tau_{1}}} ; \frac{1}{\tau_{1}} \leq t \leq \frac{1}{\tau_{2}} \\
1 \quad ; t>\frac{1}{\tau_{2}}
\end{array}\right. \\
f_{S_{2}}(t)=\left\{\begin{array}{cc}
0 \quad ; t<\frac{1}{\tau_{1}} \\
\frac{1}{\frac{1}{\tau_{2}}-\frac{1}{\tau_{1}}} ; \frac{1}{\tau_{1}} \leq t \leq \frac{1}{\tau_{2}} \\
0 \quad ; t>\frac{1}{\tau_{2}}
\end{array}\right.
\end{gathered}
$$

iii. $\quad \mathrm{N}=3$

$$
\begin{gathered}
S_{1}^{3}=\frac{X_{1}}{\tau_{1}}+\frac{X_{2}}{\tau_{2}}+\frac{X_{3}}{\tau_{3}} \\
F_{S_{1}^{3}}(t)=P\left(\frac{X_{1}}{\tau_{1}}+\frac{X_{2}}{\tau_{2}}+\frac{X_{3}}{\tau_{3}}<t\right)=\int_{-\infty}^{+\infty} P\left(\frac{X_{1}}{\tau_{1}}+\frac{X_{2}}{\tau_{2}}+\frac{X_{3}}{\tau_{3}}<t \mid X_{3}=x_{3}\right) \cdot f_{X_{3}}\left(x_{3}\right) d x_{3} \\
=2 \int_{0}^{1-x_{3}} \int_{0}^{1-} P\left(\frac{X 1}{\tau_{1}}+\frac{x_{2}}{\tau_{2}}+\frac{x_{3}}{\tau_{3}}<t\right) f_{X_{2}}\left(x_{2}\right) d x_{2} \cdot f_{X_{3}}\left(x_{3}\right) d x_{3} \\
=2 \int_{0}^{1} \int_{0}^{1-x_{3}} P\left(\frac{1-x_{3}-x_{2}}{\tau_{1}}+\frac{x_{2}}{\tau_{2}}<t-\frac{x_{3}}{\tau_{3}}\right) f_{X_{2}}\left(x_{2}\right) d x_{2} \cdot f_{X_{3}}\left(x_{3}\right) d x_{3} \\
=2 \int_{0}^{1-x_{3}} \int_{0}^{1-x_{3}} P\left(x_{2}<\frac{t-\frac{x_{3}}{\tau_{3}}-\frac{1-x_{3}}{\tau_{1}}}{\frac{1}{\tau_{2}}-\frac{1}{\tau_{1}}}\right) d x_{2} \cdot d x_{3}
\end{gathered}
$$


After integration, we obtain:

$$
F_{S_{1}^{3}}(t)=\left\{\begin{array}{c}
0 \quad ; t<\frac{1}{\tau_{1}} \\
\frac{\left(t-\frac{1}{\tau_{1}}\right)}{\left(\frac{1}{\tau_{3}}-\frac{1}{\tau_{1}}\right)} \cdot \frac{\left(t-\frac{1}{\tau_{1}}\right)}{\left(\frac{1}{\tau_{2}}-\frac{1}{\tau_{1}}\right)} ; \frac{1}{\tau_{1}} \leq t \leq \frac{1}{\tau_{2}} \\
1-\left(1-\frac{\left(t-\frac{1}{\tau_{1}}\right)}{\left(\frac{1}{\tau_{3}}-\frac{1}{\tau_{1}}\right)}\right) \cdot\left(1-\frac{\left(t-\frac{1}{\tau_{2}}\right)}{\left(\frac{1}{\tau_{3}}-\frac{1}{\tau_{2}}\right)}\right) ; \frac{1}{\tau_{2}} \leq t \leq \frac{1}{\tau_{3}} \\
1 ; t \frac{1}{\tau_{3}}
\end{array}\right.
$$

$$
f_{S_{1}^{3}}(t)=\left\{\begin{array}{c}
0 \quad ; t<\frac{1}{\tau_{1}} \\
\frac{2\left(t-\frac{1}{\tau_{1}}\right)}{\left(\frac{1}{\tau_{3}}-\frac{1}{\tau_{1}}\right)\left(\frac{1}{\tau_{2}}-\frac{1}{\tau_{1}}\right)} ; \frac{1}{\tau_{1}} \leq t \leq \frac{1}{\tau_{2}} \\
\frac{2 \cdot\left(\frac{1}{\tau_{3}}-t\right)}{\left(\frac{1}{\tau_{3}}-\frac{1}{\tau_{1}}\right)\left(\frac{1}{\tau_{3}}-\frac{1}{\tau_{2}}\right)} ; \frac{1}{\tau_{2}} \leq t \leq \frac{1}{\tau_{3}} \\
0 ; t>\frac{1}{\tau_{3}}
\end{array}\right.
$$

iv. $\quad \mathrm{N}=4$

$$
\begin{gathered}
S_{1}^{4}=\frac{X_{1}}{\tau_{1}}+\frac{X_{2}}{\tau_{2}}+\frac{X_{3}}{\tau_{3}}+\frac{X_{4}}{\tau_{4}} \\
F_{S_{1}^{4}}(t)=P\left(\frac{X_{1}}{\tau_{1}}+\frac{X_{2}}{\tau_{2}}+\frac{X_{3}}{\tau_{3}}+\frac{X_{4}}{\tau_{4}}<t\right)=\int_{-\infty}^{+\infty} P\left(\frac{X_{1}}{\tau_{1}}+\frac{X_{2}}{\tau_{2}}+\frac{X_{3}}{\tau_{3}}+\frac{X_{4}}{\tau_{4}}<t \mid X_{4}=x_{4}\right) \cdot f_{X_{4}}\left(x_{4}\right) d x_{4} \\
=3 \int_{0}^{1} \int_{0}^{1-x_{4}} P\left(\frac{X 1}{\tau_{1}}+\frac{X_{2}}{\tau_{2}}+\frac{x_{3}}{\tau_{3}}+\frac{x_{4}}{\tau_{4}}<t\right) f_{X_{3}}\left(x_{3}\right) d x_{3} \cdot f_{X_{4}}\left(x_{4}\right) d x_{4}
\end{gathered}
$$




$$
\begin{gathered}
=6 \int_{0}^{1} \int_{0}^{1-x_{4}} \int_{0}^{1-x_{4}-x_{3}} P\left(\frac{1-x_{1}-x_{2}-x_{3}}{\tau_{1}}+\frac{x_{2}}{\tau_{2}}+\frac{x_{3}}{\tau_{3}}+\frac{x_{4}}{\tau_{4}}<t\right) f_{X_{2}}\left(x_{2}\right) d x_{2} f_{X_{3}}\left(x_{3}\right) d x_{3} f_{X_{4}}\left(x_{4}\right) d x_{4} \\
=6 \int_{0}^{1} \int_{0}^{1-x_{4}} \int_{0}^{1-x_{4}-x_{3}} P\left(x_{2}<\frac{t-\frac{x_{3}}{\tau_{3}}-\frac{x_{4}}{\tau_{4}}-\frac{1-x_{3}-x_{4}}{\tau_{1}}}{\frac{1}{\tau_{2}}-\frac{1}{\tau_{1}}}\right) d x_{2} d x_{3} d x_{4}
\end{gathered}
$$

The integration exercise becomes much more complicated in the case of $\mathrm{N}=4$. The Monte Carlo approach is preferred to obtain numerical solution of the PDF for $\mathrm{N}>3$.

\section{Appendix B: Suitability measures}

As discussed in the text, various suitability measures can be used. Two possible suitability measures are:

$$
\sigma=n^{n} \cdot \prod_{i=1}^{n} x_{i} \quad \text { or } \quad \sigma=\min _{i=1 . . n}\left(x_{i}\right)
$$

If, for example, we choose the second form, we obtain:

$$
\begin{gathered}
P\left(\frac{\left|\tau-\tau_{\max }\right|}{\tau_{\max }}<d \mid \min _{i=1 . . n}\left(x_{i}\right)>y\right)=1 \\
1-n \min _{i=1 . . n}\left(x_{i}\right)>x_{i}>\min _{i=1 . . n}\left(x_{i}\right) \\
\frac{\left(1-n \min _{i=1 . . n}\left(x_{i}\right)\right) \sum_{i=1}^{n} \frac{1}{\tau_{i}}>\sum_{i=1}^{n} \frac{x_{i}}{\tau_{i}}>\min _{i=1 . . n}\left(x_{i}\right) \sum_{i=1}^{n} \frac{1}{\tau_{i}}}{\left(1-n \min _{i=1 . . n}\left(x_{i}\right)\right) n} \\
\frac{\tau_{\max }}{\left(1-n \min _{i=1 . . n}\left(x_{i}\right)\right) n}-\frac{1}{\tau}>\frac{\min _{i=1 . . n}\left(x_{i}\right) n}{\tau_{\max }}<\frac{\tau}{\tau_{\max }}-1<\frac{1}{\min _{i=1 . . n}\left(x_{i}\right) n}-1 \\
1-\frac{1}{\left(1-n \min _{i=1 . . n}\left(x_{i}\right)\right) n}>1-\frac{1}{\tau_{\max }}>1-\frac{1}{\min _{i=1 . . n}\left(x_{i}\right) n}
\end{gathered}
$$

For example, if $\min _{i=1 . . n}\left(x_{i}\right)=\frac{-(1-3 n) \pm \sqrt{1+n^{2}-6 n}}{4 n^{2}}$ then the condition above becomes: 


$$
\left|1-\frac{\tau}{\tau_{\max }}\right|<1-\frac{1}{\min _{i=1 . . n}\left(x_{i}\right) n}
$$

In the following Table, we show these two bounds for $n=10$ and different $\sigma$ values:

Table: Mixture constraints for the suitability function $\sigma=\min _{i=1 . . n}\left(x_{i}\right)$

\begin{tabular}{|ccc|}
\hline $\min _{\boldsymbol{i}=\mathbf{1 . n}}\left(\boldsymbol{x}_{\boldsymbol{i}}\right)$ & $\mathbf{1}-\frac{\mathbf{1}}{\left(\mathbf{1}-\boldsymbol{n} \mathbf{m i n}_{\boldsymbol{i} \mathbf{1 . . n}}\left(\boldsymbol{x}_{\boldsymbol{i}}\right)\right) \boldsymbol{n}}$ & $\mathbf{1}-\frac{\mathbf{1}}{\mathbf{m i n}_{\boldsymbol{i}=\mathbf{n} \boldsymbol{n}}\left(\boldsymbol{x}_{\boldsymbol{i}}\right) \boldsymbol{n}}$ \\
\hline 0.0565 & 0.7702 & -0.7702 \\
0.0885 & 0.1298 & -0.1298 \\
0.01 & 0.8889 & -9 \\
0.02 & 0.8750 & -4 \\
0.03 & 0.8571 & -2.3333 \\
0.04 & 0.8333 & -1.5 \\
0.05 & 0.8 & -1 \\
0.06 & 0.75 & -0.6667 \\
0.07 & 0.6667 & -0.4286 \\
0.08 & 0.5 & -0.25 \\
0.09 & 0 & -0.1111 \\
0.1 & 0 & - infinity \\
\hline
\end{tabular}

From this Table, we can see that if all the components have a mole fraction higher than 0.0885 then the ignition delay time of the mixture is within 13\% of the expected IDT given by Eq. 1 (main text). Unfortunately, this is a mixture of 10 components and a value of 0.0885 is very restrictive and it basically means that the mixture is almost equimolar. This observation means that the chosen measure $(\sigma)$ is not optimal, and perhaps other measures, such as the one used in the main manuscript, would give better solution. 


\section{References}

[1] Naser N, Yang SY, Kalghatgi G, Chung SH. Relating the octane numbers of fuels to ignition delay times measured in an ignition quality tester (IQT). Fuel 2017;187:117-27.

[2] Singh E, Badra J, Mehl M, Sarathy SM. Chemical Kinetic Insights into the Octane Number and Octane Sensitivity of Gasoline Surrogate Mixtures. Energy Fuels 2017;31(2):1945-60.

[3] Badra JA, Bokhumseen N, Mulla N, Sarathy SM, Farooq A, Kalghatgi G, et al. A methodology to relate octane numbers of binary and ternary n-heptane, iso-octane and toluene mixtures with simulated ignition delay times. Fuel 2015;160:458-69.

[4] Kalghatgi G, Morganti K, Algunaibet I, Sarathy M, Dibble R. Knock Prediction Using a Simple Model for Ignition Delay. SAE International; 2016.

[5] Lifshitz A. Chemical and Combustion Kinetics. Handbook of Shock Waves. San Diego: Academic Press; 2001.

[6] Lifshitz A, Scheller K, Burcat A, Skinner GB. Shock-tube investigation of ignition in methane-oxygen-argon mixtures. Combust Flame 1971;16(3):311-21.

[7] Wang Z, Mohamed SY, Zhang L, Moshammer K, Popolan-Vaida DM, Shankar VSB, et al. New insights into the low-temperature oxidation of 2-methylhexane. Proc CombustInst 2017;36(1):373-82.

[8] Ranzi E, Faravelli T, Gaffuri P, Sogaro A. Low-temperature combustion: Automatic generation of primary oxidation reactions and lumping procedures. Combust Flame 1995;102(1):179-92.

[9] Westbrook CK, Mehl M, Pitz WJ, Sjöberg M. Chemical kinetics of octane sensitivity in a spark-ignition engine. Combust Flame 2017;175:2-15.

[10] Herbinet O, Husson B, Serinyel Z, Cord M, Warth V, Fournet R, et al. Experimental and modeling investigation of the low-temperature oxidation of n-heptane. Combust Flame 2012;159(12):3455-71.

[11] AlAbbad M, Javed T, Khaled F, Badra J, Farooq A. Ignition delay time measurements of primary reference fuel blends. Combust Flame 2017;178:205-16.

[12] Hartmann M, Gushterova I, Fikri M, Schulz C, Schieß1 R, Maas U. Auto-ignition of toluene-doped n-heptane and iso-octane/air mixtures: High-pressure shock-tube experiments and kinetics modeling. Combust Flame 2011;158(1):172-8.

[13] Heufer K, Olivier H. Determination of ignition delay times of different hydrocarbons in a new high pressure shock tube. Shock Waves 2010;20(4):307-16.

[14] Burke SM, Burke U, Mc Donagh R, Mathieu O, Osorio I, Keesee C, et al. An experimental and modeling study of propene oxidation. Part 2: Ignition delay time and flame speed measurements. Combust Flame 2015;162(2):296-314.

[15] Zhou C-W, Li Y, O'Connor E, Somers KP, Thion S, Keesee C, et al. A comprehensive experimental and modeling study of isobutene oxidation. Combust Flame 2016;167:35379.

[16] Mehl M, Pitz WJ, Westbrook CK, Yasunaga K, Conroy C, Curran HJ. Autoignition behavior of unsaturated hydrocarbons in the low and high temperature regions. Proc CombustInst 2011;33(1):201-8.

[17] Khaled F, Badra J, Farooq A. Ignition delay time correlation of fuel blends based on Livengood-Wu description. Fuel 2017;209:776-86. 
[18] Livengood JC, Wu PC. Correlation of autoignition phenomena in internal combustion engines and rapid compression machines. Symp (Int) Combust 1955;5(1):347-56.

[19] Yates ADB, Viljoen CL. An Improved Empirical Model for Describing Auto-ignition. SAE International; 2008.

[20] $\mathrm{Hu}$ Z, Somers BLMT, Cracknell RF, Bradley D. Investigation of the Livengood-Wu integral for modelling autoignition in a high-pressure bomb. Combustion Theory and Modelling 2016;20(1):77-98.

[21] $\mathrm{Xu} \mathrm{R}$, Wang $\mathrm{H}$. Principle of large component number in multicomponent fuel combustion-a Monte Carlo study. Proc CombustInst 2019;37(1):613-20.

[22] Shao J, Zhu Y, Wang S, Davidson DF, Hanson RK. A shock tube study of jet fuel pyrolysis and ignition at elevated pressures and temperatures. Fuel 2018;226:338-44.

[23] Wang H, Xu R, Wang K, Bowman CT, Hanson RK, Davidson DF, et al. A physics-based approach to modeling real-fuel combustion chemistry - I. Evidence from experiments, and thermodynamic, chemical kinetic and statistical considerations. Combust Flame 2018;193:502-19.

[24] Xu R, Wang K, Banerjee S, Shao J, Parise T, Zhu Y, et al. A physics-based approach to modeling real-fuel combustion chemistry - II. Reaction kinetic models of jet and rocket fuels. Combust Flame 2018;193:520-37.

[25] AlAbbad M, Badra J, Djebbi K, Farooq A. Ignition delay measurements of a low-octane gasoline blend, designed for gasoline compression ignition (GCI) engines. Proc CombustInst 2019;37(1):171-8.

[26] Sarathy SM, Farooq A, Kalghatgi GT. Recent progress in gasoline surrogate fuels. Prog Energy Combust Sci 2018;65:67-108.

[27] Davidson D, Zhu Y, Shao J, Hanson R. Ignition delay time correlations for distillate fuels. Fuel 2017;187:26-32.

[28] Ma J, Kwak KH, Lee B, Jung D. An empirical modeling approach for the ignition delay of fuel blends based on the molar fractions of fuel components. Fuel 2016;164:305-13.

[29] Sarathy SM, Westbrook CK, Mehl M, Pitz WJ, Togbe C, Dagaut P, et al. Comprehensive chemical kinetic modeling of the oxidation of 2-methylalkanes from C7 to C20. Combust Flame 2011;158(12):2338-57.

[30] Zhang K, Banyon C, Bugler J, Curran HJ, Rodriguez A, Herbinet O, et al. An updated experimental and kinetic modeling study of n-heptane oxidation. Combust Flame 2016;172:116-35.

[31] Shen H-PS, Steinberg J, Vanderover J, Oehlschlaeger MA. A Shock Tube Study of the Ignition of n-Heptane, n-Decane, n-Dodecane, and n-Tetradecane at Elevated Pressures. Energy Fuels 2009;23(5):2482-9.

[32] Shen H-PS, Vanderover J, Oehlschlaeger MA. A shock tube study of the auto-ignition of toluene/air mixtures at high pressures. Proc CombustInst 2009;32(1):165-72.

[33] Nakamura H, Darcy D, Mehl M, Tobin CJ, Metcalfe WK, Pitz WJ, et al. An experimental and modeling study of shock tube and rapid compression machine ignition of $\mathrm{n}$ butylbenzene/air mixtures. Combust Flame 2014;161(1):49-64.

[34] Sarathy SM, Kukkadapu G, Mehl M, Javed T, Ahmed A, Naser N, et al. Compositional effects on the ignition of FACE gasolines. Combust Flame 2016;169:171-93.

[35] Reaction Design I. CHEMKIN PRO Release 15101 ed. San Diego, CA; 2010. 
[36] Frigyik BA, Kapila A, Gupta MR. Introduction to the Dirichlet distribution and related processes. Department of Electrical Engineering, University of Washignton, UWEETR2010-0006 2010.

[37] Sadooghi-Alvandi SM, Nematollahi AR, Habibi R. On the distribution of the sum of independent uniform random variables. Statistical Papers 2009;50(1):171-5.

[38] Ji W, Zhao P, He T, He X, Farooq A, Law CK. On the controlling mechanism of the upper turnover states in the NTC regime. Combust Flame 2016;164:294-302.

[39] Lee C, Ahmed A, Nasir EF, Badra J, Kalghatgi G, Sarathy SM, et al. Autoignition characteristics of oxygenated gasolines. Combust Flame 2017;186:114-28.

[40] Sarathy SM, Kukkadapu G, Mehl M, Wang W, Javed T, Park S, et al. Ignition of alkanerich FACE gasoline fuels and their surrogate mixtures. Proc CombustInst 2015;35(1):249-57.

[41] Javed T, Ahmed A, Lovisotto L, Issayev G, Badra J, Sarathy SM, et al. Ignition studies of two low-octane gasolines. Combust Flame 2017;185:152-9.

[42] Davidson DF, Shao JK, Choudhary R, Mehl M, Obrecht N, Hanson RK. Ignition delay time measurements and modeling for gasoline at very high pressures. Proc CombustInst 2019;37(4):4885-92.

[43] Bruno TJ, Laesecke A, Outcalt SL, Seelig H-D, Smith BL. Properties of a 50/50 Mixture of Jet-A+ S-8. US Department of Commerce, Technology Administration, National Institute of Standards and Technology; 2007.

[44] Vanderover J, Oehlschlaeger MA. Ignition time measurements for methylcylcohexaneand ethylcyclohexane-air mixtures at elevated pressures. Int $\mathrm{J}$ Chem Kinet 2009;41(2):82-91.

[45] Conroy C. A High Pressure Shock Tube and Rapid Compression Machine Study of nButylcyclohexane and its Mixtures with n-Heptane. Combustion Chemistry Center. Ph.D.: National University of Ireland, Galway; 2013.

[46] Davidson D, Gauthier B, Hanson R. Shock tube ignition measurements of iso-octane/air and toluene/air at high pressures. Proc CombustInst 2005;30(1):1175-82.

[47] Daley SM, Berkowitz AM, Oehlschlaeger MA. A shock tube study of cyclopentane and cyclohexane ignition at elevated pressures. Int J Chem Kinet 2008;40(10):624-34.

[48] Darcy D, Tobin CJ, Yasunaga K, Simmie JM, Würmel J, Metcalfe WK, et al. A high pressure shock tube study of n-propylbenzene oxidation and its comparison with nbutylbenzene. Combust Flame 2012;159(7):2219-32.

[49] Sarathy SM, Javed T, Karsenty F, Heufer A, Wang W, Park S, et al. A comprehensive combustion chemistry study of 2, 5-dimethylhexane. Combust Flame 2014;161(6):144459.

[50] Sirjean B, Dames E, Sheen D, You X, Sung C, Holley A, et al. A high-temperature chemical kinetic model of n-alkane oxidation. JetSurF version 2008;1.

[51] Vasu SS, Davidson DF, Hanson RK. Jet fuel ignition delay times: Shock tube experiments over wide conditions and surrogate model predictions. Combust Flame 2008;152(1-2):125-43.

[52] Burden S, Tekawade A, Oehlschlaeger MA. Ignition delay times for jet and diesel fuels: Constant volume spray and gas-phase shock tube measurements. Fuel 2018;219:312-9.

[53] Farrell J, Cernansky N, Dryer F, Law C, Friend D, Hergart C, et al. Development of an experimental database and kinetic models for surrogate diesel fuels. SAE Technical Paper; 2007. 
[54] Pitz WJ, Mueller CJ. Recent progress in the development of diesel surrogate fuels. Prog Energy Combust Sci 2011;37(3):330-50.

[55] Qian Y, Yu L, Li Z, Zhang Y, Xu L, Zhou Q, et al. A new methodology for diesel surrogate fuel formulation: Bridging fuel fundamental properties and real engine combustion characteristics. Energy 2018;148:424-47.

[56] Mueller CJ, Cannella WJ, Bruno TJ, Bunting B, Dettman HD, Franz JA, et al. Methodology for Formulating Diesel Surrogate Fuels with Accurate Compositional, Ignition-Quality, and Volatility Characteristics. Energy Fuels 2012;26(6):3284-303.

[57] Pfahl U, Fieweger K, Adomeit G. Self-ignition of diesel-relevant hydrocarbon-air mixtures under engine conditions. Symp (Int) Combust 1996;26(1):781-9.

[58] Haylett DR, Lappas PP, Davidson DF, Hanson RK. Application of an aerosol shock tube to the measurement of diesel ignition delay times. Proc CombustInst 2009;32(1):477-84.

[59] Haylett DR, Davidson DF, Hanson RK. Ignition delay times of low-vapor-pressure fuels measured using an aerosol shock tube. Combust Flame 2012;159(2):552-61.

[60] Gowdagiri S, Wang W, Oehlschlaeger MA. A shock tube ignition delay study of conventional diesel fuel and hydroprocessed renewable diesel fuel from algal oil. Fuel 2014;128:21-9.

[61] Westbrook CK, Pitz WJ, Herbinet O, Curran HJ, Silke EJ. A comprehensive detailed chemical kinetic reaction mechanism for combustion of n-alkane hydrocarbons from $\mathrm{n}$ octane to n-hexadecane. Combust Flame 2009;156(1):181-99.

[62] Biet J, Hakka MH, Warth V, Glaude P-A, Battin-Leclerc F. Experimental and Modeling Study of the Low-Temperature Oxidation of Large Alkanes. Energy Fuels 2008;22(4):2258-69.

[63] Oehlschlaeger MA, Steinberg J, Westbrook CK, Pitz WJ. The autoignition of iso-cetane at high to moderate temperatures and elevated pressures: Shock tube experiments and kinetic modeling. Combust Flame 2009;156(11):2165-72.

[64] Ranzi E, Frassoldati A, Faravelli T, Cuoci A. Lumped Kinetic Modeling of the Oxidation of Isocetane (2,2,4,4,6,8,8-Heptamethylnonane) in a Jet-Stirred Reactor (JSR). Energy Fuels 2009;23(10):5287-9.

[65] Pousse E, Porter R, Warth V, Glaude PA, Fournet R, Battin-Leclerc F. Lean methane premixed laminar flames doped by components of diesel fuel II: n-Propylcyclohexane. Combust Flame 2010;157(1):75-90.

[66] Ristori A, Dagaut P, Bakali AE, Cathonnet M. The Oxidation of N-Propylcyclohexane: Experimental Results and Kinetic Modeling. Combust Sci Technol 2001;165(1):197-228.

[67] Xu R, Wang H. Principle of large component number in multicomponent fuel combustion - a Monte Carlo study. Proc CombustInst 2018.

[68] Oehlschlaeger MA, Shen H-PS, Frassoldati A, Pierucci S, Ranzi E. Experimental and Kinetic Modeling Study of the Pyrolysis and Oxidation of Decalin. Energy Fuels 2009;23(3):1464-72.

[69] Weber BW, Pitz WJ, Mehl M, Silke EJ, Davis AC, Sung C-J. Experiments and modeling of the autoignition of methylcyclohexane at high pressure. Combust Flame 2014;161(8):1972-83.

[70] Jeremy V, A. OM. Ignition time measurements for methylcylcohexane- and ethylcyclohexane-air mixtures at elevated pressures. Int J Chem Kinet 2009;41(2):82-91. 
[71] Zhang HR, Huynh LK, Kungwan N, Yang Z, Zhang S. Combustion Modeling and Kinetic Rate Calculations for a Stoichiometric Cyclohexane Flame. 1. Major Reaction Pathways. J Phys Chem A 2007;111(19):4102-15.

[72] Mehl M, Pitz WJ, Westbrook CK, Curran HJ. Kinetic modeling of gasoline surrogate components and mixtures under engine conditions. Proc CombustInst 2011;33(1):193200.

[73] Darcy D, Nakamura H, Tobin CJ, Mehl M, Metcalfe WK, Pitz WJ, et al. A high-pressure rapid compression machine study of n-propylbenzene ignition. Combust Flame 2014;161(1):65-74.

[74] Wang H, Warner SJ, Oehlschlaeger MA, Bounaceur R, Biet J, Glaude P-A, et al. An experimental and kinetic modeling study of the autoignition of $\alpha$-methylnaphthalene/air and $\alpha$-methylnaphthalene/n-decane/air mixtures at elevated pressures. Combust Flame 2010;157(10):1976-88. 